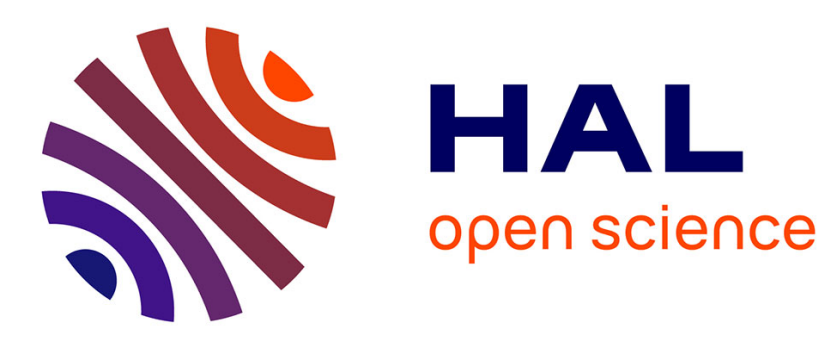

\title{
Self-Assemblies of Fe 3 O 4 Nanocrystals: Toward Nanoscale Precision of Photothermal Effects in the Tumor Microenvironment
}

Alba Nicolas-boluda, Zhijie Yang, Thomas Guilbert, Laura Fouassier, Florent Carn, Florence Gazeau, Marie Paule Pileni

\section{To cite this version:}

Alba Nicolas-boluda, Zhijie Yang, Thomas Guilbert, Laura Fouassier, Florent Carn, et al.. Self-Assemblies of Fe $3 \mathrm{O} 4$ Nanocrystals: Toward Nanoscale Precision of Photothermal Effects in the Tumor Microenvironment. Advanced Functional Materials, 2020, pp.2006824. 10.1002/adfm.202006824. hal-03003265

\section{HAL Id: hal-03003265 \\ https: / hal.sorbonne-universite.fr/hal-03003265}

Submitted on 13 Nov 2020

HAL is a multi-disciplinary open access archive for the deposit and dissemination of scientific research documents, whether they are published or not. The documents may come from teaching and research institutions in France or abroad, or from public or private research centers.
L'archive ouverte pluridisciplinaire HAL, est destinée au dépôt et à la diffusion de documents scientifiques de niveau recherche, publiés ou non, émanant des établissements d'enseignement et de recherche français ou étrangers, des laboratoires publics ou privés. 


\title{
Self-Assemblies of $\mathrm{Fe}_{3} \mathrm{O}_{4}$ Nanocrystals: Toward Nanoscale Precision of Photothermal Effects in the Tumor Microenvironment
}

\author{
Alba Nicolas-Boluda, Zhijie Yang, Thomas Guilbert, Laura Fouassier, Florent Carn, Florence Gazeau,* and \\ Marie Paule Pileni*
}

Dr. A. Nicolas-Boluda, Dr. F. Carn, Dr. F. Gazeau Laboratoire Matière et Systèmes Complexes Université de Paris CNRS UMR 7057

Paris, France E-mail: florence.gazeau@u-paris.fr Dr. A. Nicolas-Boluda, Dr. T. Guilbert, Institut Cochin, Université de Paris INSERM U1016 CNRS UMR 8104 Paris, France, Prof. Z. Yang, Key Laboratory of Colloid and Interface Chemistry of MOE School of Chemistry and Chemical EngineeringShandong University, Jinan, Shandong, China, Dr. L. Fouassier,Sorbonne Université,Inserm, Centre de Recherche Saint-Antoine, CRSA, Paris, France, Prof. M. P. Pileni, Chemistry Department, Sorbonne Université, Paris, France E-mail: mppileni@orange.fr

The ORCID identification number(s) for the author(s) of this article can be found under https://doi.org/10.1002/adfm.202006824.

$\mathrm{Fe}_{3} \mathrm{O}_{4}$ nanocrystals were self-assembled into two different conformations: colloidosome and supraball, that confer them with distinct properties determining their photo-induced heating capacities. We asses these selfassemblies for photothermal therapy, an adjuvant strategy for tumor therapy. The tumor microenvironment is an heterogeneous ecosystem including immune cells and the extracellular matrix. The interactions between photothermal therapy agents and the different components of the tumor microenvironment determine the outcome of this therapy. In this study we decorticate the fate of both colloidosomes and supraballs within the tumor microenvironment in comparison to their $\mathrm{Fe}_{3} \mathrm{O}_{4}$ nanocrystal building blocks. We highlight how these two hybrids self-assemblies target different compartments of the tumor microenvironment and trigger local photothermal damages that are inaccessible for isolated nanocrystals and not predicted by global temperature measurements.

\section{Introduction}

Self-organization of entities in 2D and 3D structures is a process frequently found in nature. For example, sodium and chloride atoms self-organize in a highly ordered structure to form $\mathrm{NaCl}$ salt, and phospholipids selfassemble in a lipid bilayer to form the cell membrane. Inspired by this natural phenomenon, chemists have developed methods to build artificial colloidal crystals of nanocrystals called supra/super-crystals. [1-4] The chemical and physical properties of such crystalline structures are neither those of the building blocks nor those of the bulk materials. They are due to either dipolar interactions between the building blocks (collective properties) ${ }^{[5,6]}$ or related to the crystalline structures (intrinsic properties). ${ }^{[7-9]}$ These unique features of selforganized nanostructures open new avenues for medical purposes, but have been poorly explored so far. For particular applications such as photoexcitation and photothermal therapy (PTT), the fine-tuning of the optical properties as well as the control of the interactions between the nanomaterial and the biological environment is of upmost importance.

Recently, a new concept to lock iron oxide nanocrystals at the liquid-liquid interface has been developed: a "Janus bilayer" shell on the ferrite nanocrystals coated with aliphatic ligand can adsorb at the liquid-liquid interface inducing the formation of flexible colloidosomes. [10] This approach avoids complicated procedures, such as those found in nanocrystal polymersomes. [11,12] When nanocrystals are not locked at the liquid-liquid interface, solid fcc spherical supraballs, are produced. Fcc spherical supracrystals have been previously obtained 
with either $6 \mathrm{~nm}$ cobalt iron oxide ${ }^{[13]}$ or colloidal silica particles. ${ }^{[14]}$ The collective properties of these new hybrid suprastructures (colloidosomes and supraballs) are still in their infancy and seem to depend on the medium of application. For example, due to the high penetration depth of visible light in fcc supracrystals dispersed in aqueous solution and effective accumulation of energy in the internal reservoir formed by the coating agents, these structures can serve as very efficient nanoheaters. ${ }^{[15]}$ This opens a broad range of potential applications in energy release including solar energy and biomedicine.

Photothermal therapy (PTT) elicit new clinical trials as adjuvant or neo-adjuvant strategy to be applied in chemo-resistant and difficult to treat tumors that have to be reduced before surgery. Photoactivable nanomaterials including plasmonic metallic nanoparticles (i.e. gold nanoshells), ${ }^{[16]}$ carbon absorbing nanomaterials (i.e. carbon nanotubes, graphene and analogues) or iron oxide nanoparticles [17] are remotely activated by a laser which penetrate the tissue generating a controlled hyperthermia in the target region. In order to be usable in clinics, a PTT nanoagent must absorb optical wavelengths in the tissue transparency windows once in the tumor environment, and fulfil criteria of low toxicity to healthy organs, easy functionalization and scale-up, and favorable biodistribution and life cycle in vivo. ${ }^{[18]}$ However, there is plenty of room for improvement of their heating capacity and fine control of the biological outcomes of nano-hyperthermia that strongly depend on the interactions of nanostructures with the local biological environments. In this respect, iron oxide nanoparticles are particularly attractive due to their natural metabolization by endogenous proteins, high biocompatibility and clinical approval of several formulations that are combined with unique superparamagnetic properties for magnetic resonance imaging, photoacoustic tomography, magnetic manipulation or magnetic hyperthermia as well as iron related redox reactivity and light to heat conversion. Whereas iron oxide nanoparticles are susceptible to both magnetic and light activation to produce local heating, the photothermal strategy has proved more efficient to induce tumor hyperthermia at low dosage. [19-25]

In solid tumors, nanoparticles encountered not only tumor cells but different components of the tumor microenvironment that include stromal cells (among which we can find fibroblasts or immune cells) and a copious lattice of extracellular matrix. The intimate interactions of the nanomaterials with the heterogeneous ecosystem of the tumor will dictate their tumor penetration, local distribution of nanoparticles, local heating efficiency, and the ultimate biological damages and mechanisms of resistance that are induced. Nevertheless, little is known on how nanomaterials interact with the tumor microenvironment and how their structural properties can modulate these interactions, their heating capacity and the PTT-induced biological outcomes. Particularly, the use of self-assembled nanocrystals forming organized suprastructures is still a blank field despite their attractive properties. In a recent paper, we have shown that flexible colloidosomes, rigid supraballs and their isolated building blocks differently interact with tumor cells, resulting in distinct intracellular distribution. Remarkably, self-assemblies allow to optimize the lysosomal density and localization of iron oxide nanocrystals and to maintain nanocrystal organization within the lysosomes.[26] Whether the organization of the selfassemblies translates into specific photothermal properties in biological environment is currently unknown. 
The present study aims to evaluate how the specific features of self-organized nanostructures can influence their efficiency as photothermal therapy agents in different biological models recapitulating the tumor microenvironment, including cellular models, ex vivo and in vivo tumor models. We highlight the remarkable result that organic inorganic self-assemblies of nanocrystals can target different components of the tumor microenvironment with respect to individual nanocrystals. Moreover, self-assemblies generate local thermal damages that are inaccessible for isolated nanocrystals and not predicted by global temperature measurements.

\section{Results and Discussion}

\subsection{Ferrite Colloidosomes and Supraballs}

Hydrophobic ferrite nanocrystals (from now on $\left.\mathrm{Fe}_{3} \mathrm{O}_{4} \mathrm{NCs}\right)$ coated with oleic acid $\left(\mathrm{OA}, \quad\left[\mathrm{CH}_{3}-\left(\mathrm{CH}_{2}\right)^{-}\right.\right.$ $\left.\left.\mathrm{CH}=\mathrm{CH}-\left(\mathrm{CH}_{2}\right)_{7}-\mathrm{COOH}\right]\right)$ are characterized by an inverted spinel structure. By ligand exchange process $\mathrm{Fe}_{3} \mathrm{O}_{4}$ NCs are coated with dopamine and dispersed in aqueous solution. Whatever the coating agent, the average diameter of $\mathrm{Fe}_{3} \mathrm{O}_{4} \mathrm{NCs}$ are $10 \pm 1 \mathrm{~nm}$ (Figure 1A and Figure S1A, Supporting Information).

By mixing $\mathrm{Fe}_{3} \mathrm{O}_{4} \mathrm{NCs}$ coated with $\mathrm{OA}$ dispersed in chloroform and dodecyl trimethylammonium bromide

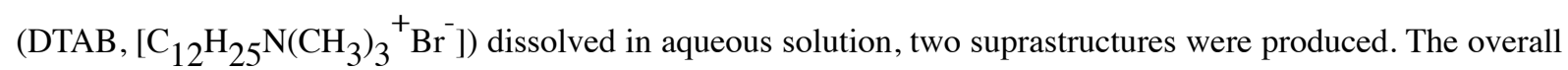
procedure remained the same except the presence or not of octadecene $\left(\mathrm{ODE},\left[\mathrm{CH}_{3}-\left(\mathrm{CH}_{2}\right)_{15}{ }^{-} \mathrm{CH}^{-} \mathrm{CH}_{2}\right]\right)$ in chloroform.

In presence of ODE, hollow self-assembled $\mathrm{Fe}_{3} \mathrm{O}_{4} \mathrm{NCs}$ structures, named colloidosomes, consist on one or a few layers of $\mathrm{Fe}_{3} \mathrm{O}_{4} \mathrm{NCs}$ (less than 4) with $170 \pm 90 \mathrm{~nm}$ as average diameter (Figure 1 and Figure S1B, Supporting Information). The inner region is made by the tail part of OA strongly bound, via the carboxyl group, to the surface of the $\mathrm{Fe}_{3} \mathrm{O}_{4}$ NCs. In contrast, the outer shell is composed of DTAB, ODE and OA. Strong hydro- phobic interactions between the alkyl chains as well as the double bonds of OA and ODE favored the dispersion of suprastructures in aqueous solution.

In absence of ODE during the mixture of the two solutions mentioned above, instead of colloidosomes, spherical solid self-assemblies of $\mathrm{Fe}_{3} \mathrm{O}_{4} \mathrm{NCs}$ in fcc crystalline structures called supraballs with an average diameter of 69 $\pm 15 \mathrm{~nm}$ were produced (Figure 1C and S1C). The contrast change in the TEM image (Figure 1C) is characteristic of the step edge structure of the assembled $\mathrm{Fe}_{3} \mathrm{O}_{4} \mathrm{NCs}$, as previously observed for fcc cobalt iron oxide and silicaparticles. [13,14]

The nanomechanical properties of these suprastructures, load-depended in aqueous solution, show that colloidosomes have a higher flexibility, deformation, stiffness and elastic moduli than supraballs. Presence of 
ODE molecules in the shell of the colloidosome induces an increase in deformation and adhesion forces at the edges. [26]

Below we compare the photothermal properties of $\mathrm{Fe}_{3} \mathrm{O}_{4} \mathrm{NCs}$ and either colloidosomes or supraballs, all dispersed in aqueous solution. Note these nanostructures keep their integrities in size, size distribution, structure and $\mathrm{pH}$ in the range from 5 to 8 for more than three years.

\subsection{Suprastructures Photothermal Properties: Apparent Contra- diction between the Global Heating and}

\section{Cell Death}

To evaluate the photo-induced heating properties of $\mathrm{Fe}_{3} \mathrm{O}_{4} \mathrm{NCs}$, colloidosomes and supraballs, we first compared the absorption spectra of the suprastructures and dispersed $\mathrm{Fe}_{3} \mathrm{O}_{4} \mathrm{NCs}$ in aqueous solution. Unexpectedly, the suprastructure absorption spectra considerably dropped compared to their building blocks (Figure S2, Supporting Information). The photo-activated heating of the hybrid structures or dispersed $\mathrm{Fe}_{3} \mathrm{O}_{4} \mathrm{NCs}$ was obtained by subjecting $100 \mu \mathrm{L}$ of suspension at fixed iron con- centration $\left(150 \mu \mathrm{g} \mathrm{mL}{ }^{-1}\right)$ to an $808 \mathrm{~nm}$ laser power $(1 \mathrm{~W}$ $\mathrm{cm}^{-2}$ ) for $5 \mathrm{~min}$. The temperature increment was the largest for supraballs $\left(10.9{ }^{\circ} \mathrm{C}\right)$, followed by $\mathrm{Fe}_{3} \mathrm{O}_{4} \mathrm{NCs}$ $\left(8.8^{\circ} \mathrm{C}\right)$, whereas the colloidosomes heated by less than $2{ }^{\circ} \mathrm{C}$ (Figure S3, Supporting Information). According to the drop of the suprastructure absorption spectra compared to that of dispersed $\mathrm{Fe}_{3} \mathrm{O}_{4} \mathrm{NCs}$, we could expect a lower temperature increment for both hybrids compared to $\mathrm{Fe}_{3} \mathrm{O}_{4}$ NCs. However, it was previously observed that $\mathrm{Fe}_{3} \mathrm{O}_{4}$ NCs self-assembled in fcc superlattices act as nanoheaters embedded in a thermal reservoir formed by the coating agents.[15] This could explain the difference in the temperature increment between supraballs

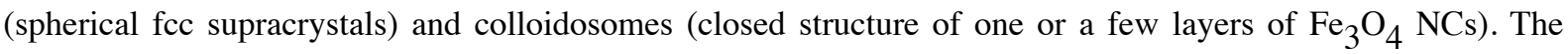
rather large value obtained with $\mathrm{Fe}_{3} \mathrm{O}_{4} \mathrm{NCs}$ compared to colloidosomes can be explained by the large difference in the number of absorbed photons at $808 \mathrm{~nm}$. 

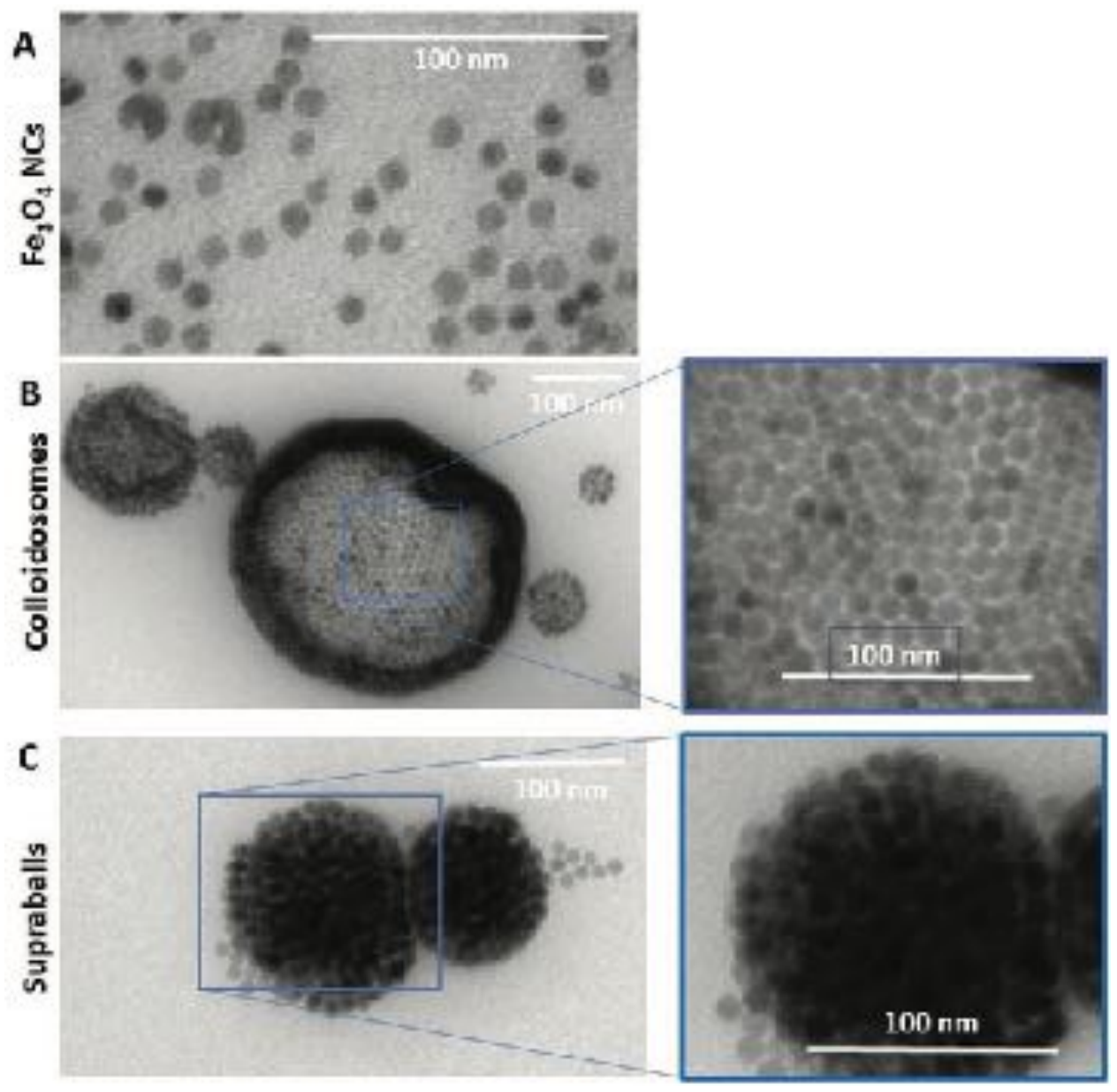

Figure 1. CryoTEM images of A) $\mathrm{Fe}_{3} \mathrm{O}_{4}$ NCs, B) colloidosomes, and C) supraballs.

In our previous paper, [26] by using self-assembled nanostructures such as colloidosomes and supraballs, we developed a new concept to investigate their intracellular fate. To evaluate the effect of internalization by tumor cells on the global heating efficiency of $\mathrm{Fe}_{3} \mathrm{O}_{4} \mathrm{NCs}$, colloidosomes and supraballs, A431 human epidermoid carcinoma cells were incubated with the nanostructures at an iron concentration of $28 \mu \mathrm{g} / \mathrm{mL}$ for $24 \mathrm{~h}$ (Figure $2 \mathrm{~A}) .{ }^{[28]}$ The cells were then washed carefully to discard the excess of $\mathrm{Fe}_{3} \mathrm{O}_{4} \mathrm{NCs}$ that had not been internalized and one million of cells were pelleted and resuspended in $100 \mu \mathrm{L}$ of culture medium before irradiation with an $808 \mathrm{~nm}$ laser in the same experimental conditions as for the nanostructures in suspension. Dispersed $\mathrm{Fe}_{3} \mathrm{O}_{4} \mathrm{NCs}$ heating efficiency was significantly higher to that of supraballs and colloidosomes once internalized in cells. From initial temperature of $25^{\circ} \mathrm{C}$, [29], cells reach a plateau temperature (in about $200 \mathrm{~s}$ ) of $38.4,33.5$ and $28^{\circ} \mathrm{C}$ for $\mathrm{Fe}_{3} \mathrm{O}_{4} \mathrm{NCs}$, supraballs and colloidosomes, respectively (Figure 2B-D). Colloidosomes are therefore the least efficient for a global heating when suspended in water or internalized in cells. 
A

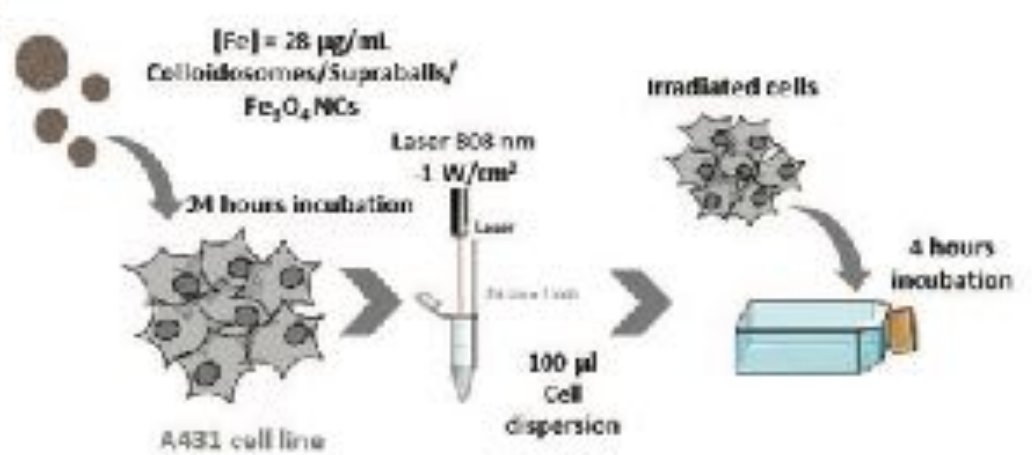

B
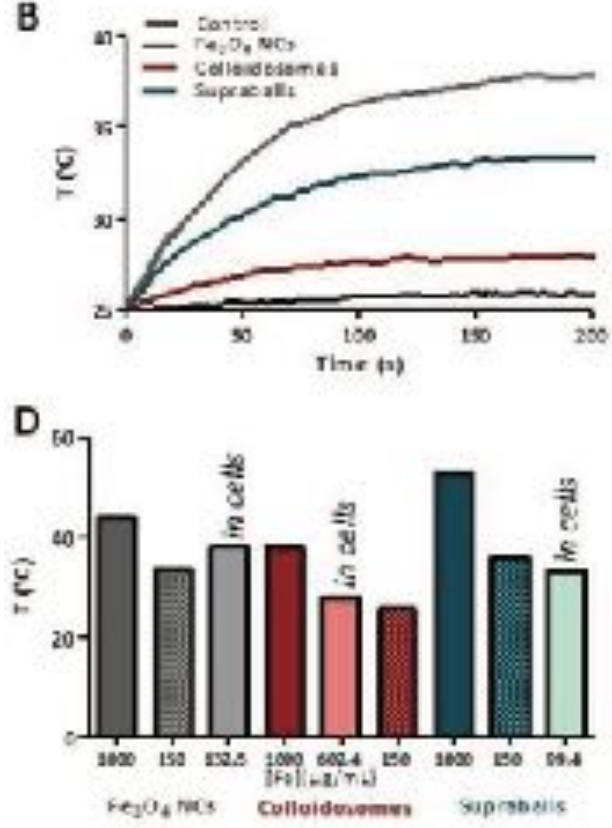

$\mathbf{F}$
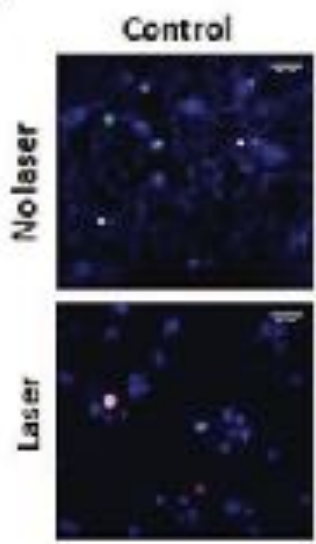

C

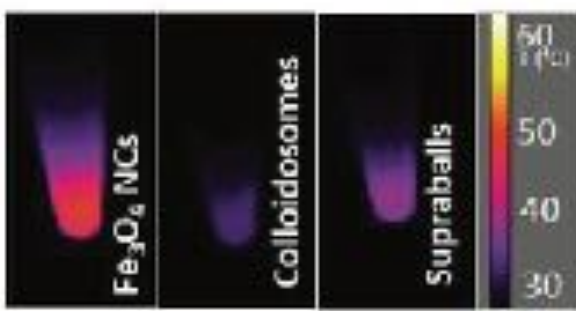

E

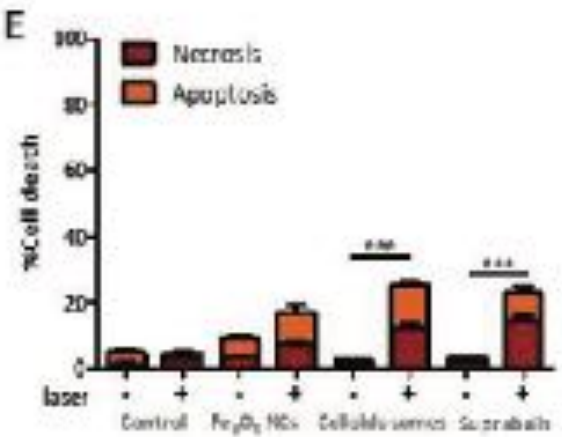

\section{Colloidosames Supraballs}
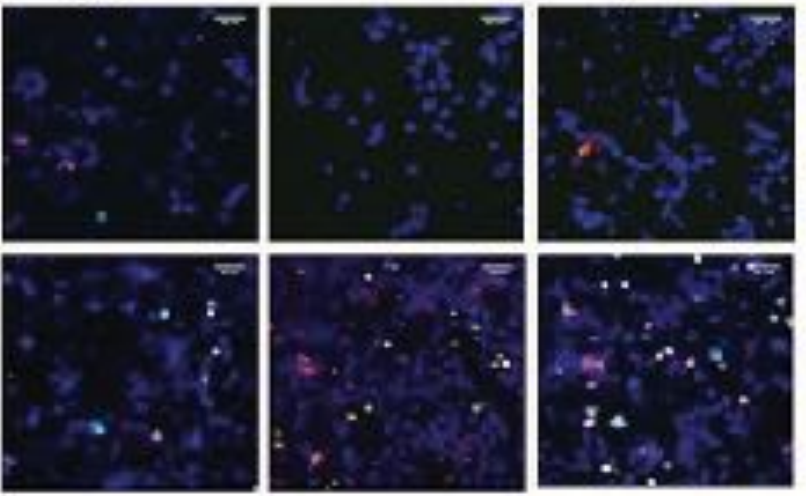

Figure 2. Evaluation of $\mathrm{Fe}_{3} \mathrm{O}_{4} \mathrm{NCs}$, colloidosomes and supraballs heating capacity in A431 cells. A) Scheme of the experimental setup to evaluate the global effect of laser irradiation on cell pellets. After $10 \mathrm{~min}$ laser irradiation of the nanoparticle-loaded cell pellet, cells are redeposited in cell culture flasks for $4 \mathrm{~h}$ before evaluating the cell death. B) Temperature increase in a pellet of 1 million cells having internalized $\mathrm{Fe}_{3} \mathrm{O}_{4} \mathrm{NCs}$, colloidosomes and supraballs and dispersed in $100 \mu \mathrm{L}$ of PBS upon irradiation with an $808 \mathrm{~nm}$ laser $\left(1 \mathrm{~W} \mathrm{~cm}^{-2}\right)$. C) Infrared thermal images of cell pellet captured at $5 \mathrm{~min}$ of $808 \mathrm{~nm}$ laser irradiation. D) Temperature increase of cell pellets compared to that of aqueous suspension of $\mathrm{Fe}_{3} \mathrm{O}_{4} \mathrm{NCs}$, colloidosomes and supraballs at two different concentrations $[\mathrm{Fe}]=150$ and $1000 \mu \mathrm{g} \mathrm{mL}{ }^{-1}$. The concentration of Fe in cell pellets is calculated from ICP-AES quantifications. E) Percentage of cell necrosis and apoptosis upon laser exposition (or not) for $10 \mathrm{~min}$ of cell pellet described above. Results shown as mean \pm SEM (20-30 images per condition, $n=3$ ). One-way ANOVA, Kruskal-Walis, ***p-value $<0.001$. F) Representative fluorescence images of A431 cells $4 \mathrm{~h}$ after laser irradiation. Cells were stained with Hoechst 33342 (cell nuclei, blue), YO-PRO (apoptotic cells) and propidium iodide (necrotic cells). Scale bar $=50 \mu \mathrm{m}$. 
A

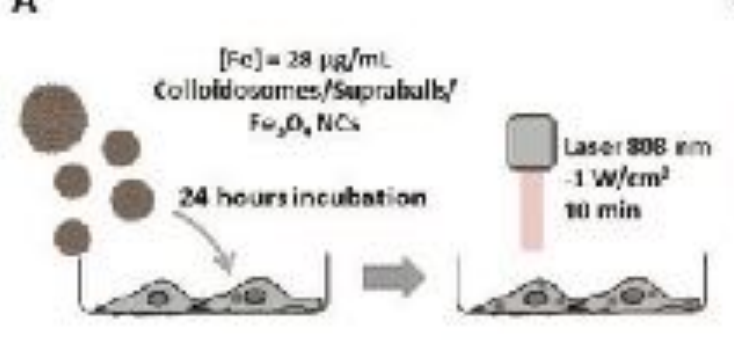

B

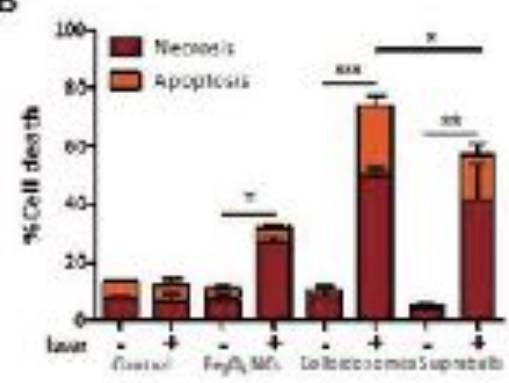

C
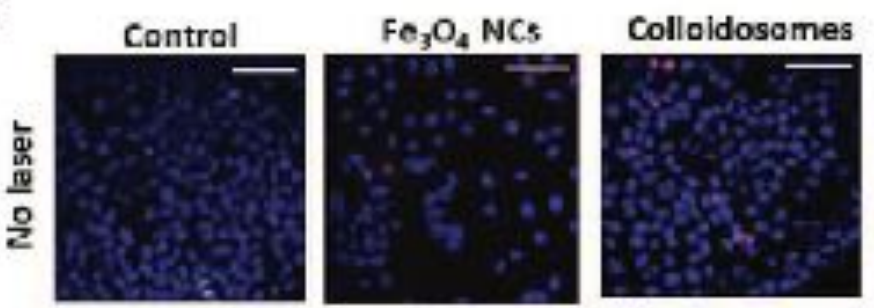

Supraballs
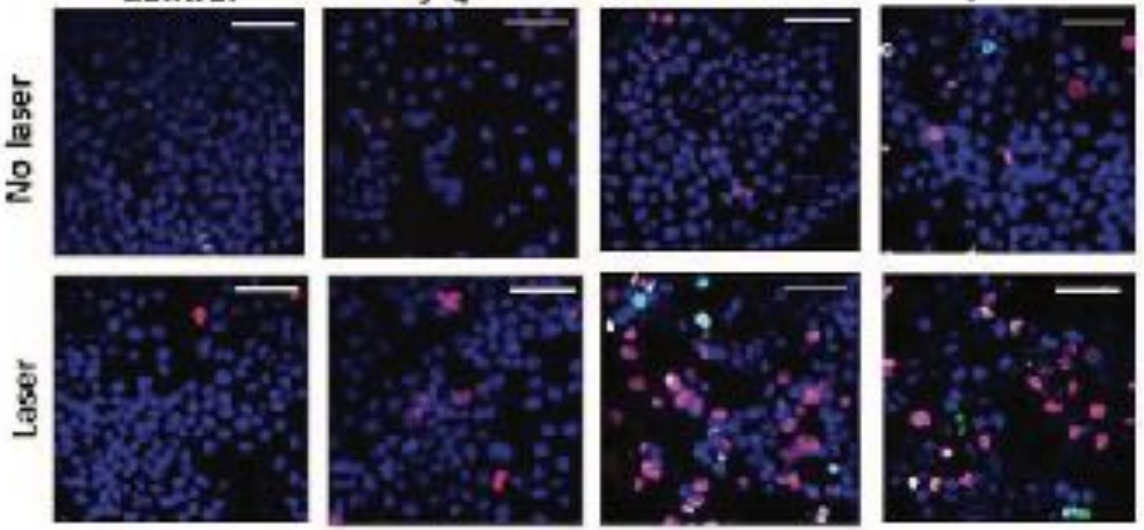

Figure 3. Evaluation of the local cellular damages induced by $\mathrm{Fe}_{3} \mathrm{O}_{4} \mathrm{NCs}$, colloidosomes and supraball-mediated PTT in cell monolayers 4 h post- irradiation. A) Scheme of the experimental setup to evaluate the local effects. $\mathrm{A} 431$ cells were incubated overnight with $\mathrm{Fe}{ }_{3} \mathrm{O}_{4} \mathrm{NCs}$, colloidosomes and supraballs, and after rinsing, they were irradiated as monolayer with an $808 \mathrm{~nm}$ laser for 10 min. The cell damaged was evaluated $4 \mathrm{~h}$ post-irradiation. B) Percentage of cell necrosis and apoptosis caused by $\mathrm{Fe}_{3} \mathrm{O}_{4}$ NCs, colloidosomes and supraballs-mediated PTT in cell monolayers. Results shown as mean \pm SEM (20-30 images per condition, $n=6)$. One-way ANOVA, Kruskal-Walis, $* p$-value $<$ $0.05, * * p$-value $<0.01, * * * p$-value $<0.001$. C) Representative fluorescence images of A431 cells. Cells were stained with Hoechst 33342 (cell nuclei, blue), YO-PRO (apoptotic cells) and propidium iodide (necrotic cells). Scale bar $=50 \mu \mathrm{m}$.

Apart from this global heating efficiency of nanostructures submitted to irradiation, the important outcome for therapy is the biological effects of $\mathrm{Fe}_{3} \mathrm{O}_{4} \mathrm{NCs}$-mediated heating. We thus quantified the cellular damages related to PTT, that might arise from the global heating of the tissue or cell pellet, or from more local thermal damages induced in the vicinity of the heat nanosources. Indeed, it has been shown that the temperature increase close to the heat nanosources is much higher than the macroscopic temperature in the surrounding medium. ${ }^{[30,31]}$ For this purpose, we evaluate thermal damages on cells in two different laser irradiation set-ups: i) in the pellet of NC-loaded cells (as described above) which combines local intracellular heating with global temperature increase in the pellet measured by thermal imaging, and ii) on monolayers of cells having internalized the $\mathrm{Fe}_{3} \mathrm{O}_{4}$ $\mathrm{NCs}$ for which the global temperature is thermalized by the particle-free culture medium at $37^{\circ} \mathrm{C}$ (Figure $3 \mathrm{~A}$ ). In the latter set-up, only local effects of intracellular heating can be expected.

Cell apoptosis and necrosis were assessed through the evaluation of the membrane permeability to fluorescent dyes. Hoechst 33342 stains the condensed chromatin of live cells, this allows the quantification of all cells. YOPROTM dye can enter cells under apoptosis whilst, propidium iodide cannot, it only stains dead necrotic cells. The staining pattern resulting from the simultaneous use of these three dyes allows to distinguish alive, apoptotic and necrotic cells populations by fluorescence microscopy represented in Figures $2 \mathrm{~F}$ and $3 \mathrm{C}$ and quantified in Figures 2E\&3B. As previous studies demonstrated the detection of cell death apoptosis 4-5 hours post 
irradiation, ${ }^{[32]}$ cells that have been pelleted and irradiated were then put back in culture for 4 hours before cell death assessment (Figure 2A). Cells having internalized the different nanostructures without laser irradiation did not show any significant enhancement in apoptosis or necrosis level in comparison to the control cells, irradiated or not, showing that the nanostructures or the laser exposure did not affect cell viability itself. This confirms our previous study [26] investigating the fate of the same nanostructures up to 8 days post-labeling, showing no significant toxicity in A431 cells up to concentration of $112 \mu \mathrm{g} / \mathrm{mL}$ in absence of irradiation.

Cells having internalized isolated $\mathrm{Fe}_{3} \mathrm{O}_{4}$ NCs show slightly enhanced level of apoptosis and necrosis after irradiation, but the difference with non-irradiated cells is not statistically significant. In contrast, colloidosome and supraball-loaded cells feature a significant enhancement of the apoptosis (more than $15 \%$ of total cell number) and necrosis level $(\sim 15 \%)$ after irradiation. These results are surprising considering the lower global temperature of the cell pellet for supraballs and colloidosomes in comparison to $\mathrm{Fe}_{3} \mathrm{O}_{4} \mathrm{NCs}$ (Figures 2B-C). This suggests that supraballs and to a larger extent colloidosomes could induce local thermal damages independently of the global temperature increment in the cell pellet. This has to be related to previous data [15] from which it was demonstrated that the light absorption in such nanostructures, dispersed in aqueous solution, initiates a chain energy transfer having various degree of freedom coupled together. In vitro, the efficiency of supraballs is expected to be larger than colloidosomes. However, in cells, the colloidosome shape is not retained and the nanocrystals self -assembled in large domains and consequently in first approximation we could assume, but not quantify, that energy penetration is almost an even larger for colloidosomes than supraballs.

To isolate thermal damages that arise from intracellular local heating, thermalized cell monolayers were exposed to the laser and cell death was quantified in the same conditions as for the cell pellet (Figure 3A). There was no effect of apoptosis or necrosis in absence of laser irradiation, but we observed significant increase of apoptosis/ necrosis level after irradiation for the three types of nanostructures. The level of cell damage induced by direct irradiation of cell monolayers was significantly higher as compared to that in pellet form, although no macroscopic heating can be measured. Even though the laser irradiation experienced by each cell can be higher than in the cell pellet as there is no light screening by cells and nanoparticles absorption, we expect in this set up only local effect of intracellular nanoheaters. Remarkably, despite colloidosomes have low global heating performance in aqueous solution and even lower in cells, colloidosome-mediated intracellular local absorption induces the highest levels of cell damage compared to $\mathrm{Fe}_{3} \mathrm{O}_{4} \mathrm{NCs}$ and to supraballs (Figure $3 \mathrm{~B}, \mathrm{C}$ ). $\mathrm{Fe}_{3} \mathrm{O}_{4} \mathrm{NCs}$, despite exhibiting higher heating efficiency both in aqueous solution and in cell pellet, induce less cellular damage upon irradiation of cell monolayers. Overall, the two self-assemblies of $\mathrm{Fe}_{3} \mathrm{O}_{4} \mathrm{NCs}$ clearly induce massive cell death: $74 \%$ and $57 \%$ of cell damage (both necrosis and apoptosis) induced by colloidosome and supraball-mediated PTT, respectively (Figure 3B), in com- parison, to less than $35 \%$ for dispersed $\mathrm{Fe}_{3} \mathrm{O}_{4} \mathrm{NCs}_{\text {. }}$ This experi- ment clearly demonstrates that self-assemblies of $\mathrm{Fe}_{3} \mathrm{O}_{4} \mathrm{NCs}$, once internalized by cells, can elicit massive local damages that provoke cell apoptosis and necrosis without global heating of the environment. 
At this point we asked the following question: What is the origin of the apparent contradiction between the global heating efficiency and the biological outcome on cells? To answer such question, we highlighted the intracellular distribution of the $\mathrm{Fe}_{3} \mathrm{O}_{4} \mathrm{NCs}$. In our previous study, [26] we described important differences in the intracellular fate of $\mathrm{Fe}_{3} \mathrm{O}_{4} \mathrm{NCs}$ internalized as dispersed $\mathrm{Fe}_{3} \mathrm{O}_{4}$ NCs or as self-assemblies in the form of colloidosomes and supraballs up to 8 days post labeling (see Figure 4 for intracellular distribution at 24 h). Upon cell internalization, dispersed $\mathrm{Fe}_{3} \mathrm{O}_{4} \mathrm{NCs}$ tend to aggregate into endosomes that fuse with lysosomes, forming uncontrolled fractal structures similar to those obtained by diffusion-limited aggregation. In contrast, supraballs and colloidosomes conserve their organized structures over at least 8 days once internalized by tumor cells demonstrating that self-organization of $\mathrm{Fe}_{3} \mathrm{O}_{4} \mathrm{NCs}$ could withstand intracellular trafficking and the harsh acidic environment of lysosomes. In addition, supraballs and colloidosomes self-assemblies maximize the intralysosomal density of $\mathrm{Fe}_{3} \mathrm{O}_{4} \mathrm{NCs}$ (surface density of $52 \%$ and $34 \%$, respectively) in comparison to $4 \%$ for isolated $\mathrm{Fe}_{3} \mathrm{O}_{4}$ NCs. Moreover, looking at the spatial distribution of $\mathrm{Fe}_{3} \mathrm{O}_{4} \mathrm{NCs}$ within the lysosomes, a much higher percentage of $\mathrm{Fe}_{3} \mathrm{O}_{4} \mathrm{NCs}$ were located within $100 \mathrm{~nm}$ of the lysosomal membrane after colloidosome internalization (up to $48 \%$ ) compared to that of dispersed $\mathrm{Fe}_{3} \mathrm{O}_{4} \mathrm{NCs}(9 \%)$ and to a minor extend compared to supraballs (20\%), as illustrated in Figure 4. [26] Such local accumulation of $\mathrm{Fe}_{3} \mathrm{O}_{4}$ NCs close to the lysosome membrane could explain that larger local damages could be obtained with self-assemblies in comparison to dispersed $\mathrm{Fe}_{3} \mathrm{O}_{4} \mathrm{NCs}$. In addition to the spatial density of $\mathrm{Fe}_{3} \mathrm{O}_{4} \mathrm{NCs}$, their ordered structure into the lysosome, inherited from the self-organization of the assembly, might favor an accumulation of energy within these structures. Indeed, as demonstrated earlier by ultra-fast optical spectroscopy and semiclassical modeling, ${ }^{[15]}$ the dilution of the metallic phase in the hybrid self-assemblies enable to increase the penetration depth of visible light in comparison to homogeneous metallic NCs of similar size, thus enabling an energy load in the assembly. The same study revealed that coating agents of $\mathrm{Fe}_{3} \mathrm{O}_{4} \mathrm{NCs}$ act at short time as a reservoir of energy due to the tiny distance between nanocrystals and thermal transfer that propagates preferentially within the assembly. This reservoir effect and thermal resistance of the hydrophobic organic phase consequently induce an increase of the localized heating in the self-assemblies compared to the fractal aggregates of $\mathrm{Fe}_{3} \mathrm{O}_{4} \mathrm{NCs}$. Hence, we hypothesize that the optimal accumulation and local density of $\mathrm{Fe}_{3} \mathrm{O}_{4} \mathrm{NCs}$ in lysosomes, their sustained compacity in lysosome and the affinity of the colloidosome shell for the lysosomal membrane can collectively explain the enhanced local damages that were observed upon irradiation, inducing massive cell death. The role of lipid bilayers and organic coating as a thermal barrier that favor local accumulation of energy has been demonstrated before using nano-thermometry. ${ }^{[33]}$ Here, we observe a direct biological consequence of the energy accumulation in the lysosome membrane due to the close proximity of the lysosome membrane to the absorbing $\mathrm{Fe}_{3} \mathrm{O}_{4} \mathrm{NCs}_{\mathrm{s}}$ colloidosomes and supraballs. This accumulation may induce lysosome swelling and membrane permeabilisation much more efficiently than for isolated $\mathrm{Fe}_{3} \mathrm{O}_{4} \mathrm{NCs}$, without significant global heating. We thus conclude that the optimization of $\mathrm{Fe}_{3} \mathrm{O}_{4} \mathrm{NC}$ density in lysosomes and proximity to the lysosome membrane, together with the high energy accumulation within the hydrophobic shell of colloidosomes or the hydrophobic core of the supraballs enhance local hot spots inducing cell death. Our study clearly demonstrates that cell damages are not directly 
related to the global heating of the environment but rather to the local energy accumulation that depends on ultrastructural distribution of $\mathrm{Fe}_{3} \mathrm{O}_{4} \mathrm{NCs}$ among themselves and within the lysosome. These data agree with previous study showing that cancer cells can be particularly sensitive to agents which induce lysosomal cell death through lysosome membrane permeabilisation or disruption. ${ }^{[34]}$ It results in the activation of apoptosis signaling pathways and contributes to the amplification of death signals.[35] Lysosome membrane permeabilization can be triggered by a wide variety of agents, one of them being local heating. [36,37] In addition, we have quantified in our previous paper [26] that colloidosomes induce a significant enhancement of the lysosome size at $24 \mathrm{~h}$ post labeling without inducing toxicity in absence of irradiation. Thus following laser stimulation, the local heating might trigger enhanced lysosome swelling, affecting more easily the lysosome integrity than with supraballs and with isolated nanocrystals, as observed in Figure 4B. 

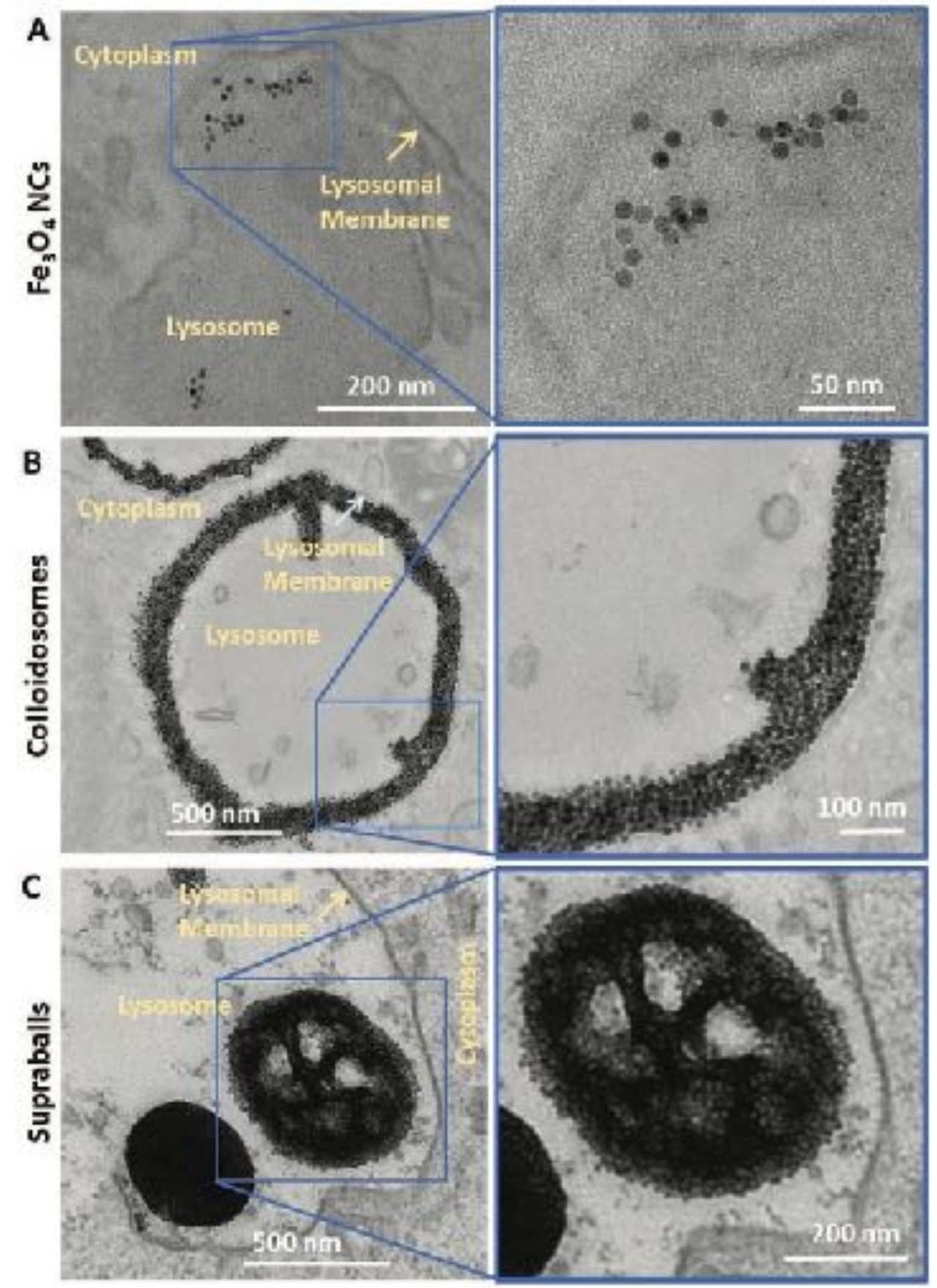

Figure 4. Colloidosome and supraball intracellular distribution in $\mathrm{A} 431$ cells. TEM images of $\mathrm{A}) \mathrm{Fe}_{3} \mathrm{O}_{4} \mathrm{NC}$, B) colloidosome and C) supraball-loaded cells $24 \mathrm{~h}$ after incubation illustrating the distinct intralysosomal distribution of nanocrystals.

\subsection{Suprastructures: Photothermal Properties in the In Vivo Tumor Microenvironment}

To test the feasibility of photothermal therapy mediated by self-assembled nanostructures in solid tumor, $\mathrm{Fe}_{3} \mathrm{O}_{4}$ NCs, colloidosomes and supraballs were injected intratumorally (i.t.) in subcutaneous tumors of murine breast cancer model MET-1. [38] The i.t. administration was chosen for two reasons. Firstly, it is a clinically relevant option for tumors that should be shrink before surgery to improve local control (neoadjuvant treatment). Percutaneous or endoscopic administration of nanoparticles has been achieved in many solid tumors such as soft tissue sarcoma, breast, pancreatic or gastrointestinal cancers and endoscopic and intraluminal light illumination 
is also feasible through the same procedures. ${ }^{[39-42]}$ Secondly the local administration of nanoparticles avoids the massive off-target accumulation of nanoparticles associated with intravenous or intra-arterial injection, minimize systemic toxicity and maximize the tumor concentration of nano-heaters. It is also the best option for comparing nanostructures that may have very different biodistribution and access to the tumor when injected intravenously. Here, the same mass of iron ([Fe]= $150 \mu \mathrm{g}$ in $50 \mu \mathrm{L}$ injected volume) was infused in tumors of approximately 150-200 $\mathrm{mm}^{3}$ which allowed a head to head comparison of the different nanostructure distribution in the tumor microenvironment and the outcome of light exposition. Injection of nanomaterials was performed in a unique injection point with a very slow infusion through $27 \mathrm{G}$ needle to maximize the distribution of nanostructures which were let for $24 \mathrm{~h}$ to diffuse and to be processed by cells of the tumor microenvironment before irradiation. $24 \mathrm{~h}$ after i.t. administration, tumors were exposed for 15 minutes to an $808 \mathrm{~nm}$ laser at a power of $2 \mathrm{~W} / \mathrm{cm}^{2}$. The tumors' surface temperature was monitored with a near infrared camera (Figure 5A). A significant increase in the tumors' surface temperature was observed with all nanostructures (plateau temperature of $\mathrm{T}=45,44$ and $43^{\circ} \mathrm{C}$ for supraballs, $\mathrm{Fe}_{3} \mathrm{O}_{4} \mathrm{NCs}$ and colloidosomes) (Figure 5B) in comparison to the laser-exposed non-injected tumors. 24 hours after laser irradiation, tumors were harvested and the local effect of $\mathrm{Fe}_{3} \mathrm{O}_{4} \mathrm{NCs}$, colloidosomes and supraballs-mediated PTT was evaluated using histology. Tumors were stained with Perls' Prussian Blue staining that allowed the detection of iron in tissue samples, in order to localize the $\mathrm{Fe}_{3} \mathrm{O}_{4} \mathrm{NCs}$ within the tissue. They were also stained with hematoxylin eosin saffron (HES) staining, hematoxylin stained the cell nuclei in blue, eosin stains the extracellular matrix and the cytoplasm in pink, whilst saffron allows the highlighting of collagen fibers (stained in yellow/orange). This trichromatic stain allows a general evaluation of a tissue sample and identification of anomalies such as the presence of necrotic regions. The presence of necrotic regions was identified for each of the conditions (Figures 5C-D). The basal level of tumor necrosis without laser exposure was about $13 \%$ regardless of the nanostructures injected or not. However, we observed striking differences in the PTT-induced necrosis level depending on the nanostructures inside the tumors. Even more surprisingly, the necrosis level did not correlate with the tumor temperature increase. Actually, the largest necrosis extension (64\%) was observed for colloidosome-treated tumors which however heat at only $43^{\circ} \mathrm{C}$ for less than 15 min under laser exposure. Supraball-mediated PTT at the same laser power induced a 50\% necrosis extension for a surface temperature of $45^{\circ} \mathrm{C}$ (Figures $5 \mathrm{C}-5 \mathrm{D}$ ). $\mathrm{Fe}_{3} \mathrm{O}_{4} \mathrm{NCs}$ on the other side, induced a much lower level of tissue damage $(24 \%)$ while the temperature plateaued to $44^{\circ} \mathrm{C}$. This evidenced again that the level of global hyperthermia applied to a given tumor does not necessary translate to a higher level of cellular damage of the tumor tissue. Importantly we observe that hybrids (colloidosomes and supraballs) induce a significant increase in tissue necrosis extension ( $>50 \%$ of the tissue) after a single laser exposition and 15 min of mild hyperthermia, while the biological outcome of their individual building blocks in similar experimental conditions and macroscopic temperature increase is not significant. These results at the tissue level in tumors fully correlates with the results obtained in the experiments described above at the cellular level, suggesting superior toxicity of intracellular heating mediated by self-assemblies in the tumor tissue. 

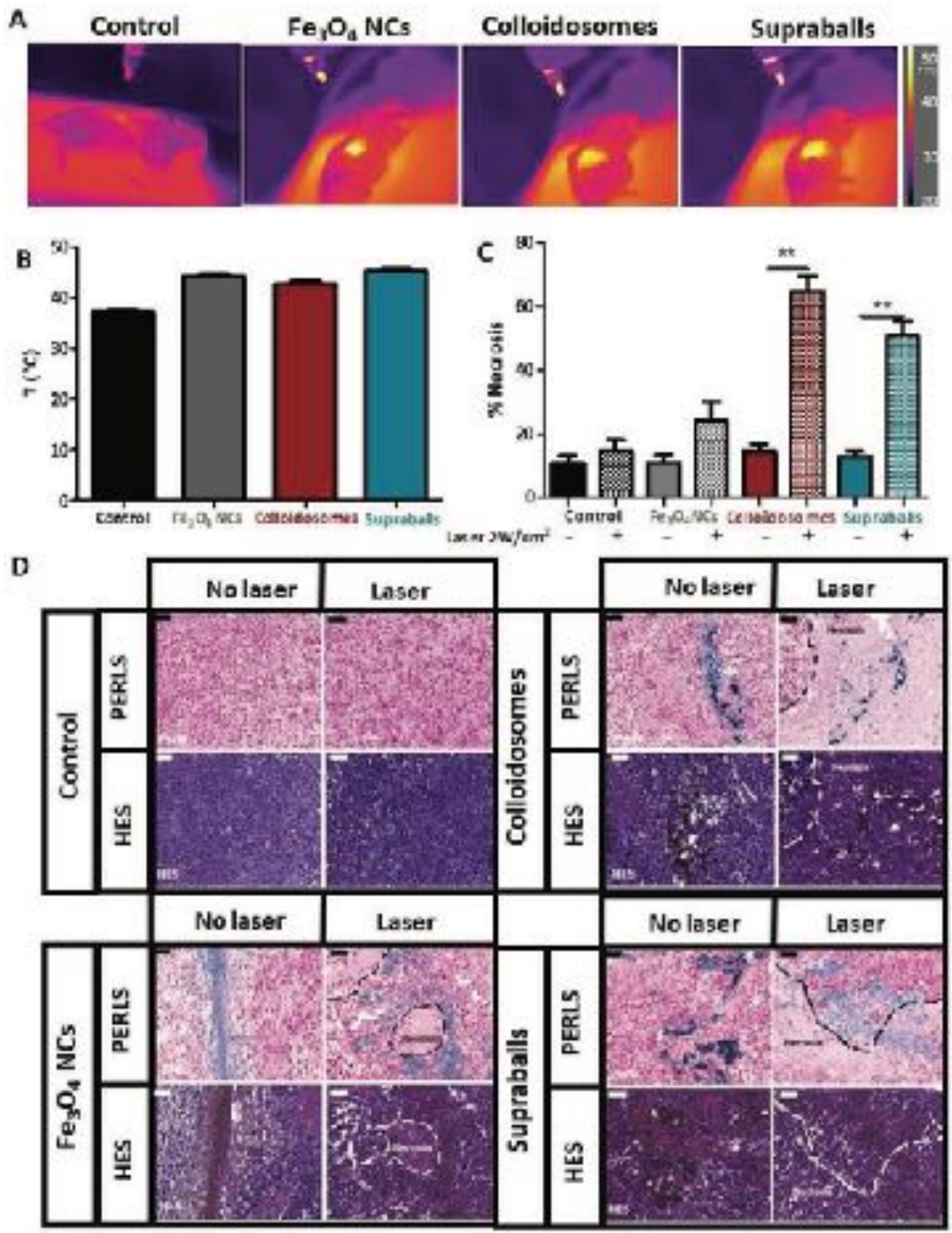

Figure 5. Colloidosome and supraball-mediated photothermal therapy in vivo. A) In vivo infrared thermal images of tumors injected with $150 \mu \mathrm{g}$ colloidosomes or supraballs and exposed $15 \mathrm{~min}$ to an $808 \mathrm{~nm}$ laser at $2 \mathrm{~W} \mathrm{~cm}(n=5)$. C) Quantification of the percentage of necrotic areas in MET-1 tumor in each of the tested conditions $(n=5)$. One-way ANOVA, Kruskal-Walis, $* p$-value $<0.05, * * p$-value $<0.01$. D) Histological (Perls and HES staining) analysis of $\mathrm{Fe}_{3} \mathrm{O}_{4} \mathrm{NCs}$, colloidosome and supraball injected MET-1 tumors $24 \mathrm{~h}$ after laser irradiation or without laser exposure. Scale bar $=50 \mu \mathrm{m}$. Nanoparticles appearing in blue with Perls staining are located in the tumor. Necrotic areas underlined by dashed line can be observed in tumors treated with laser close to $\mathrm{NC}$ localizations.

\subsection{Suprastructures Modulate the Distribution of $\mathrm{Fe}_{3} \mathrm{O}_{4} \mathrm{NCs}$ in the Tumor Microenvironment}

Tumors do not consist exclusively on tumor cells, but on a complex ecosystem including stromal cells (endothelial cells, fibroblasts and immune cells) and extracellular matrix (ECM) composed of a multitude of biomolecules including collagen and hyaluronic acid, in what is called the tumor microenvironment. ${ }^{[43]}$ The role of the heterogeneity of the tumor microenvironment in chemoresistance has been evidenced in the last decade [44] 
but somewhat overlooked in the field of nanoparticle-mediated therapies since the precise nanoparticle localization and local effects have been barely investigated.[45] Considering that the components of the tumor might interacts differently with the nanostructures, we thought to investigate the differences in tissue distribution and local photothermal effects that could arise specifically from the hybrid self-assemblies. Importantly, we could observe striking differences one day after i.t. injection in the MET-1 breast tumor environment (Figure 6). As already mentioned, Perls staining detect iron in blue, the hematoxylin stains cell nuclei blue, eosin stains the extracellular matrix and cytoplasm in pink, $\mathrm{Fe}_{3} \mathrm{O}_{4}$ NCs appears in yellow/orange on $\mathrm{HES}$ staining and $\mathrm{F} 4 / 80$ detect macrophages in brown. When isolated $\mathrm{Fe}_{3} \mathrm{O}_{4} \mathrm{NCs}$ were injected in tumors (Figure 6, left), they mainly localized in the extracellular space, in close contact with the ECM fibers. Such localization along collagen fibers was previously observed for iron oxide nanocubes of $20 \mathrm{~nm} .{ }^{[46]} \mathrm{In}$ addition, a recruitment of F4/80 positive macrophages (indicated by blue arrows in Figure 6) is induced in the vicinities of $\mathrm{Fe}_{3} \mathrm{O}_{4} \mathrm{NCs}$. Contrastingly colloidosomes are mainly internalized by tumor cells (Figure 6, middle), whilst supraball location is both intracellular and extracellular (Figure 6, right). This revealed that the different nanostructure architectures severely impact the nanostructure distribution in the heterogeneous tumor environment. Particularly the hybrids, and more particularly colloidosomes have a more potent tropism for tumor cells in comparison to their dispersed building blocks $\left(\mathrm{Fe}_{3} \mathrm{O}_{4} \mathrm{NCs}\right)$ which distributed mostly in between collagen fibers in this breast tumor model. This is an important finding to explain the extended necrosis damage inflicted by colloidosome and supraballmediated PTT in comparison to the insignificant effect of dispersed $\mathrm{Fe}_{3} \mathrm{O}_{4} \mathrm{NCs}$, despite similar temperature increase. Colloidosomes and to a lesser extent supraballs could effectively induce deleterious local heating within tumor cells due to their specific accumulation, while $\mathrm{Fe}_{3} \mathrm{O}_{4} \mathrm{NCs}$, in addition to a lower intracellular toxicity after irradiation, were mostly located extracellularly with lesser impact on tumor cells.

To decorticate further the interactions of the nanostructures with the heterogeneous populations of the tumor microenvironment, we compared in vitro the internalization of dispersed $\mathrm{Fe}_{3} \mathrm{O}_{4} \mathrm{NCs}$, colloidosomes and supraballs with separated monoculture of tumor cells (A431 - human epidermoid carcinoma cells), macrophages (RAW 264.7- murine macrophages) and fibroblasts (hTERT-HSC-human immortalized liver fibroblasts). Iron quantification by ICP-AES displayed in Figure 7 shows that supraballs could transfer more iron in macrophages than colloidosomes and dispersed $\mathrm{Fe}_{3} \mathrm{O}_{4}$ NCs. In contrast, iron capture in tumor cells was higher with colloidosomes than with supraballs and dispersed $\mathrm{Fe}_{3} \mathrm{O}_{4} \mathrm{NCs}$. Fibroblasts also present higher uptake of iron with colloidosomes and to a lesser extent with supraballs in comparison with dispersed $\mathrm{Fe}_{3} \mathrm{O}_{4} \mathrm{NCs}_{\text {shat }}$ show more than ten times smaller uptake.

Our comparative study emphasizes the poor efficacy of dispersed $\mathrm{Fe}_{3} \mathrm{O}_{4} \mathrm{NCs}$ to accumulate into tumor cells or into fibroblasts, even if these cells are separately exposed to the $\mathrm{Fe}_{3} \mathrm{O}_{4} \mathrm{NCs}$ in absence of ECM. Importantly, the only cell type that accumulates significant amount of dispersed $\mathrm{Fe}_{3} \mathrm{O}_{4} \mathrm{NCs}(>50 \mathrm{pg})$ are the macrophages in line with the histological observations in tumors. Remarkably the self-assembly of $\mathrm{Fe}_{3} \mathrm{O}_{4} \mathrm{NCs}$ within prescribed suprastructures can reverse this trend since colloidosomes are also substantially up taken by tumor cells and fibroblasts. 
Such differential cell internalization depending both on cell types and nanostructure architectures can be interpreted in view of their different mechanical properties, such as stiffness and deformability. Macrophages are key actors of immunity and first line of defense against pathogens, xenobiotics or senescent cells. It has been reported that macrophages can sense the rigidity of phagocytic targets, such as red blood cells that become more

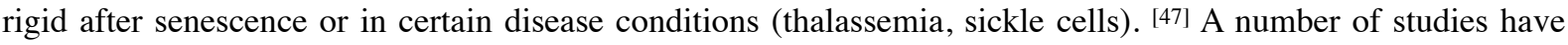
shown that stiffer particles are internalized to a higher extent than softer particles by macrophages and other immune cells. ${ }^{[48,49]}$ Our results show that stiffer supraballs are also more internalized by macrophages than colloidosomes with slightly lower Young's modulus and a more deformable structure. [27]

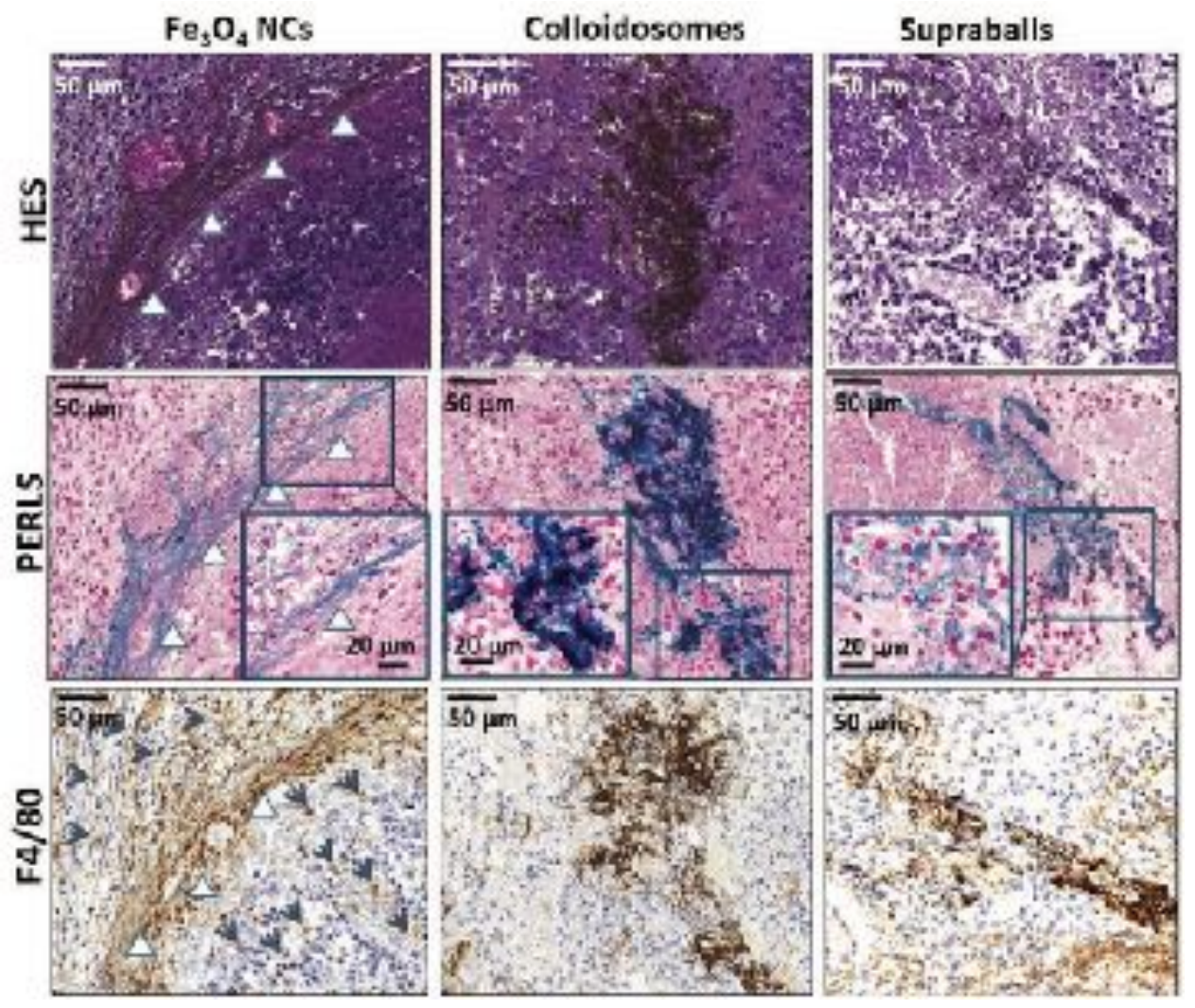

Figure 6. Histological (Perls and HES staining) and immunological (F4/80 labeling) analysis of MET-1 tumors $24 \mathrm{~h}$ after intratumoral injection of $\mathrm{Fe}_{3} \mathrm{O}_{4} \mathrm{NCs}$, colloidosomes and supraballs. Insets display magnification of the gray square. Iron appears in blue with Perls staining and in yellow/ orange in HES and F4/80 images. White arrows indicate ECM fibers along which most $\mathrm{Fe}_{3} \mathrm{O}_{4} \mathrm{NCs}$ are located. Gray arrows indicate the recruitment of macrophages (F4/80 brown labeling). Colloidosomes have mostly intracellular localization (see the inset on Perls staining) and supraballs have both intracellular and extracellular localizations.

One explanation for increased uptake of supraballs by phagocytic cells is that colloidosomes may undergo deformation in response to phagocytosis forces exerted by the cells which locally decreases their radius of curvature and makes phagocytosis more energetically costly and more difficult to achieve than with rigid undeformable supraballs. ${ }^{[50]}$ In contrast to macrophages, the comparison of tumor cell uptake of soft/hard particles has shown complex findings without general trend emerging. ${ }^{[51,52]}$ In this case, epidermoid carcinoma cells show a preference for soft and deformable colloidosomes. This is also in line with our finding in the 
in vivo MET-1 breast tumor model confirming higher uptake of tumor cells for colloidosomes. To sum up, both in the heterogeneous microenvironment of tumors and in conditions in which only one cellular component is exposed to the nanostructures, the self-assembled colloidosomes have the unique potential to maximize their accumulation by tumor cells and fibroblasts in comparison to ECM and macrophages. This is the first demonstration that the self-organization of $\mathrm{Fe}_{3} \mathrm{O}_{4} \mathrm{NCs}$ and the resulting mechanical properties can be used to modulate the distribution of $\mathrm{Fe}_{3} \mathrm{O}_{4} \mathrm{NCs}$ in the tumor microenvironment.

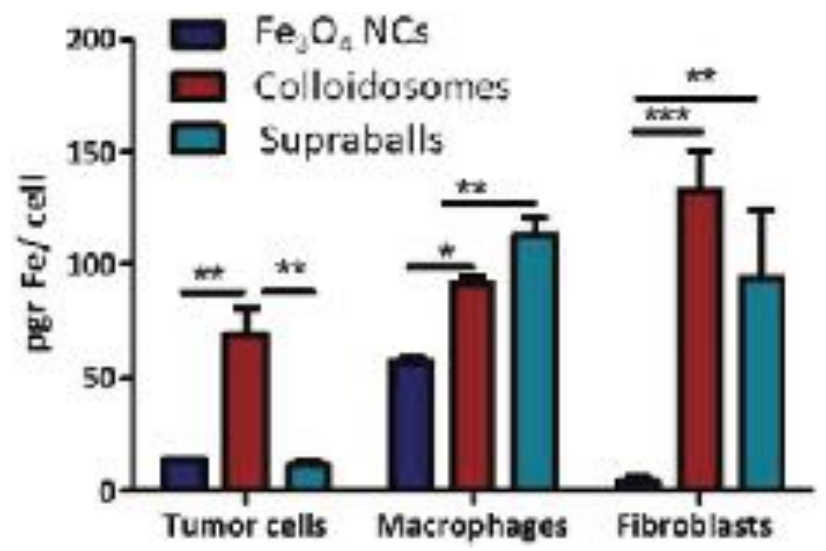

Figure 7. Iron quantification measured by ICP-AES in tumor cells (A431 cell line), macrophages (RAW 264.7 cell line) and fibroblasts (hTERT-HSC immortalized line) after $24 \mathrm{~h}$ exposition to $\mathrm{Fe}_{3} \mathrm{O}_{4} \mathrm{NCs}$ colloidosomes or supraballs at $[\mathrm{Fe}]=28 \mu \mathrm{g} \mathrm{mL}(n=3)$. One-way ANOVA, Kruskal-Walis, * $p$-value $<0.05,{ }^{* *} p$-value $<0.01$, *** $p$-value $<0.001$.

The ECM is another important component of the tumor stroma that is differently expressed and organized depending on the origin and progression of the tumor. In order to investigate the interaction between the nanostructures and the ECM, we set up an in vitro model consisting of fibroblast sheets secreting ECM over stimulation with ascorbic acid. [53] The abundant ECM fibers surrounding fibroblasts can be observed on TEM image in Figure 8A. These fibroblast sheets were exposed to $\mathrm{Fe}_{3} \mathrm{O}_{4} \mathrm{NCs}$, colloidosomes or supraballs overnight, followed by careful washing. As in the in vivo tumor, $\mathrm{Fe}_{3} \mathrm{O}_{4} \mathrm{NCs}$ were mainly located along the $\mathrm{ECM}$ in between fibroblasts (Figure 8B). The colloidosomes were all internalized by fibroblasts and were absent from ECM (Figure 8C). Supraballs could be found in both compartments (Figure 8D). These results confirm that in the hybrid $\mathrm{ECM} /$ cellular environment, $\mathrm{Fe}_{3} \mathrm{O}_{4} \mathrm{NCs}$ are barely internalized by fibroblasts, whilst colloidosomes show the opposite behavior. Notably, supraballs are less internalized by fibroblasts than colloidosomes. The mechanical properties of colloidosomes featuring lower Young modulus/stiffness and larger flexibility than supraballs may favor internalization by fibroblasts, while supraballs are more easily trapped in ECM fibers, as well as isolated $\mathrm{Fe}_{3} \mathrm{O}_{4} \mathrm{NCs}$. Such observations on fibroblast sheets nicely correlate with those shown previously in the complex microenvironment of the tumor (Figure 6) in which $\mathrm{Fe}_{3} \mathrm{O}_{4} \mathrm{NCs}$ were mainly located in the ECM, colloidosomes internalized in the tumor cells and supraballs both located in intracellular and extracellular compartments. 


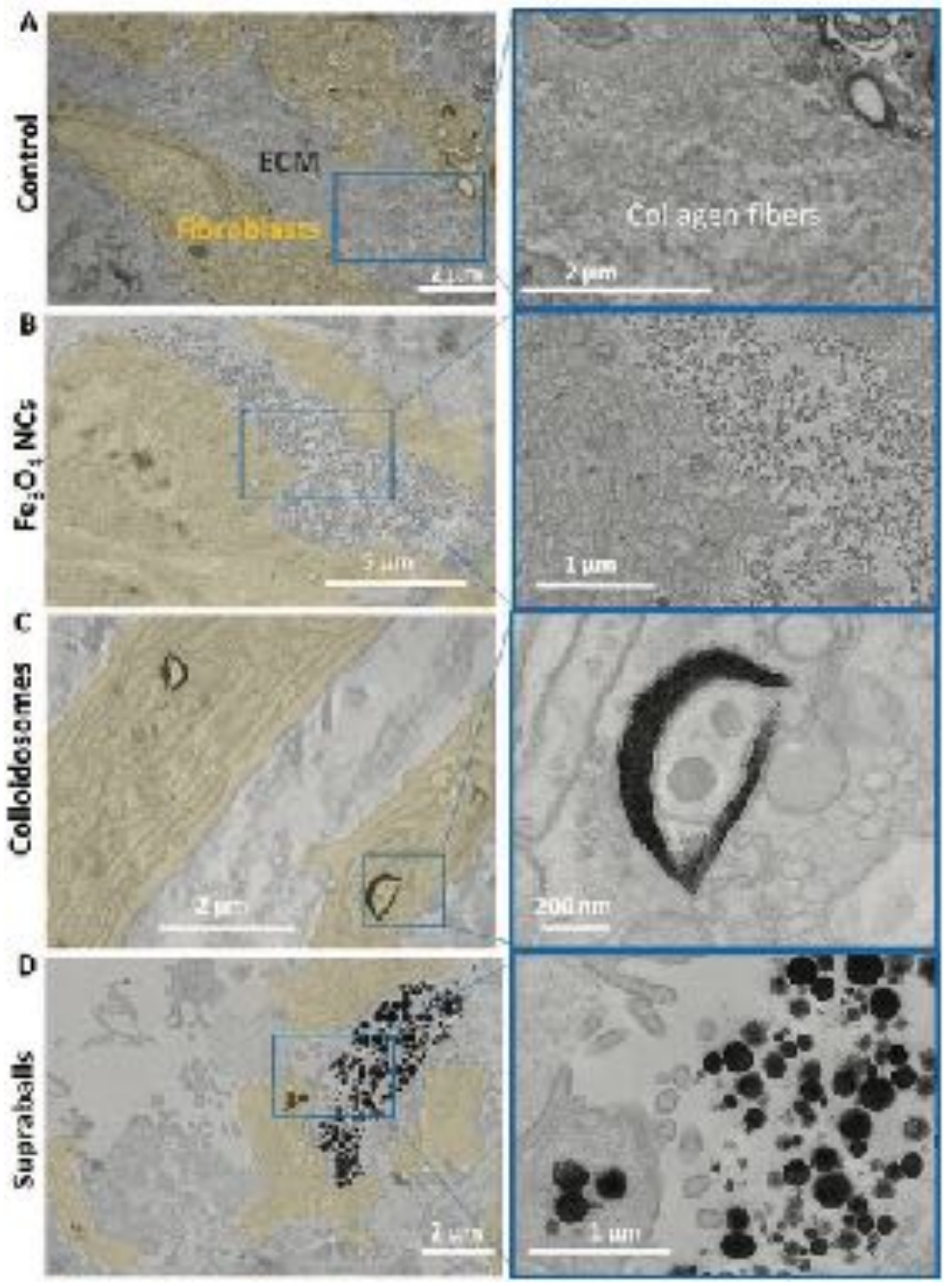

Figure 8. TEM images on $70 \mathrm{~nm}$ microtome sections of $\mathrm{Fe}_{3} \mathrm{O}_{4} \mathrm{NCs}$, colloidosome or supraballs distribution in the fibroblast/ECM in vitro model. The fibroblasts are highlighted in yellow in the lower magnification images. Images on the right are magnification of the white quadrant on image on the left. A) Control fibroblast sheet with dense ECM. B) $\mathrm{Fe}_{3} \mathrm{O}_{4} \mathrm{NCs}$ distribution on fibroblast-ECM in vitro model, $\mathrm{Fe}_{3} \mathrm{O}_{4} \mathrm{NCs}$ mainly accumulate in the ECM compartment. C) Colloidosomes distribution on fibroblast-ECM in vitro model, mainly internalized in fibroblasts. D) Supraball distribution on fibroblast-ECM in vitro model, distributed both within fibroblasts and within the ECM.

\subsection{Suprastructures: Photothermal Effects on the Tumor Extracellular Matrix}

Due to the important role of ECM in promoting tumor progression, chemoresistance and immune exclusion, the ECM is recognized as a multicomponent target for advanced therapeutic strategies. Previous studies have showed that carbon-nanotube mediated PTT could induce the local denaturation of collagen fibers in tendon and in tumors.[54] We thus tested the photothermal effects of the two hybrids and $\mathrm{Fe}_{3} \mathrm{O}_{4} \mathrm{NCs}$ on ECM in different organotypic models. In order to visualize the direct effect of PTT on the ECM of real tumors, we used ex vivo fresh $350 \mu \mathrm{m}$ tumor slices incubated for 2 hours with $\mathrm{Fe}_{3} \mathrm{O}_{4} \mathrm{NCs}$, colloidosomes and supraballs (Figure 9B) and then exposed to $808 \mathrm{~nm}$ laser at $2 \mathrm{~W} / \mathrm{cm}^{2}$. The EGI-1 tumor model, a human bile duct desmoplastic cancer, was chosen for its abundant ECM (unlike the MET-1 tumor model previously used) and linear organization of collagen fibers that can be observed and quantified using second harmonic generation (SHG) two photon microscopy (Figure 9A). In comparison to the non-irradiated tumors, the amount of collagen SHG signal was 
significantly reduced after irradiation of tumor slices exposed to colloidosomes (Figure 9C), but not to $\mathrm{Fe}_{3} \mathrm{O}_{4}$ NCs or supraballs. Analyses of SHG images with the CT-FIRE software [54] also show a significant decrease in collagen fiber length of tumors exposed to colloidosomes and irradiated (Figure 9D), that can be related to fiber denaturation induced by localized heating (Figure 9A, blue arrows).

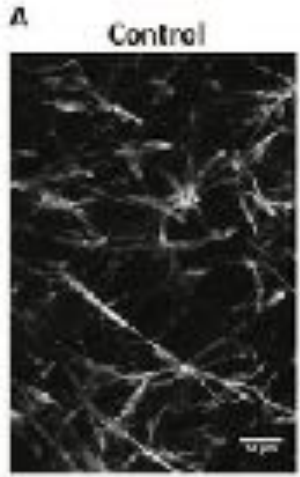

$\mathbf{B}$

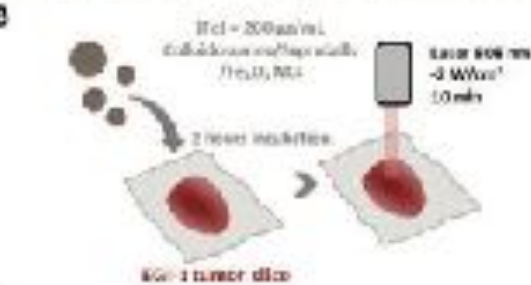

D

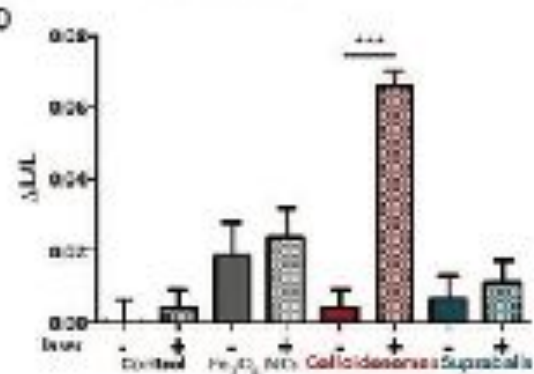

$\mathrm{re}_{5} \mathrm{O}_{4} \mathrm{NCs}$
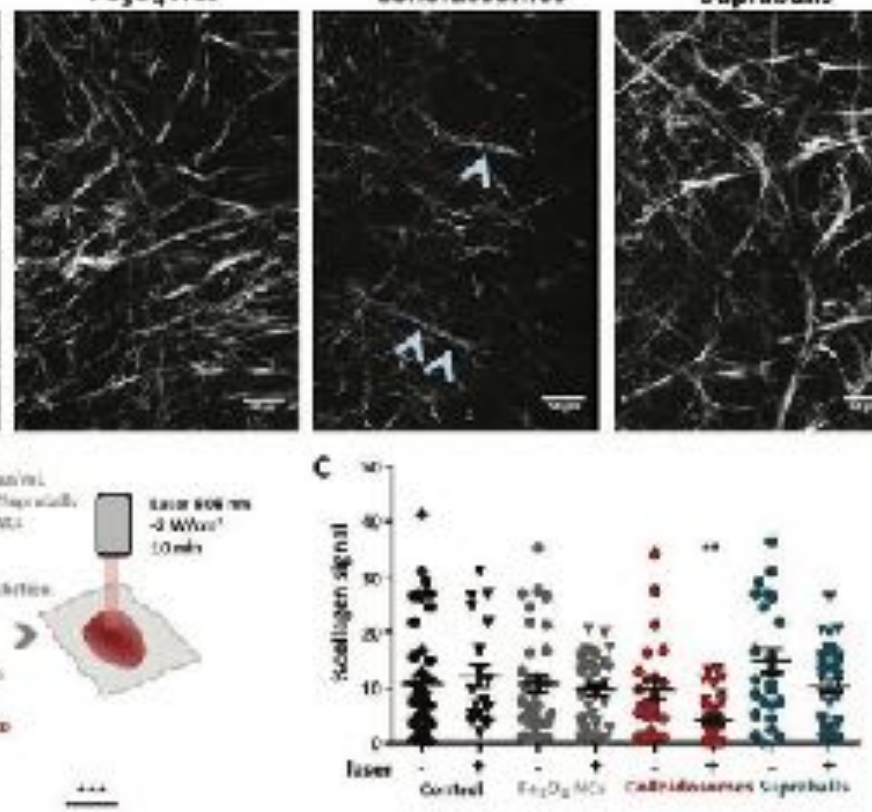

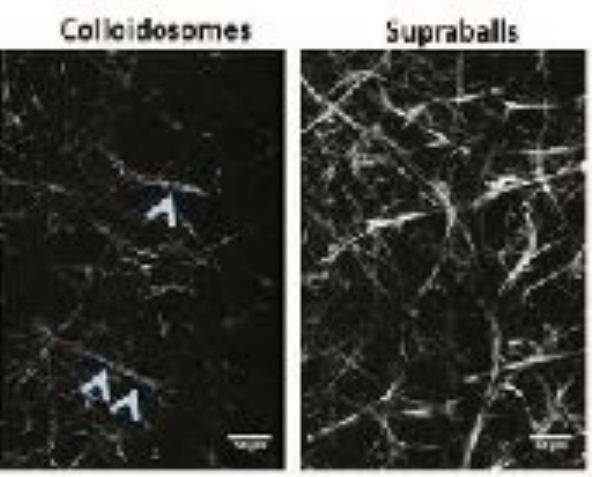

\section{.}


irradiated tendon. After laser exposure, SEM observations confirm that colloidosome-mediated PTT induces the formation of "holes" on the dense collagen network (Figure 10C) close to colloidosomes. The same kind of holes are also seen in samples that had undergone supraball-mediated PTT (Figure 10D). This means that supraballmediated PTT also induces collagen denaturation but to a lesser extent, probably not enough to be detected with SHG microscopy in these conditions. These experiments focusing on collagen matrix on tumor and tendon slices clearly reveal the colloidosomes as the most efficient light-activated nanoheaters to induce local denaturation of the collagen fibers in our experimental conditions.

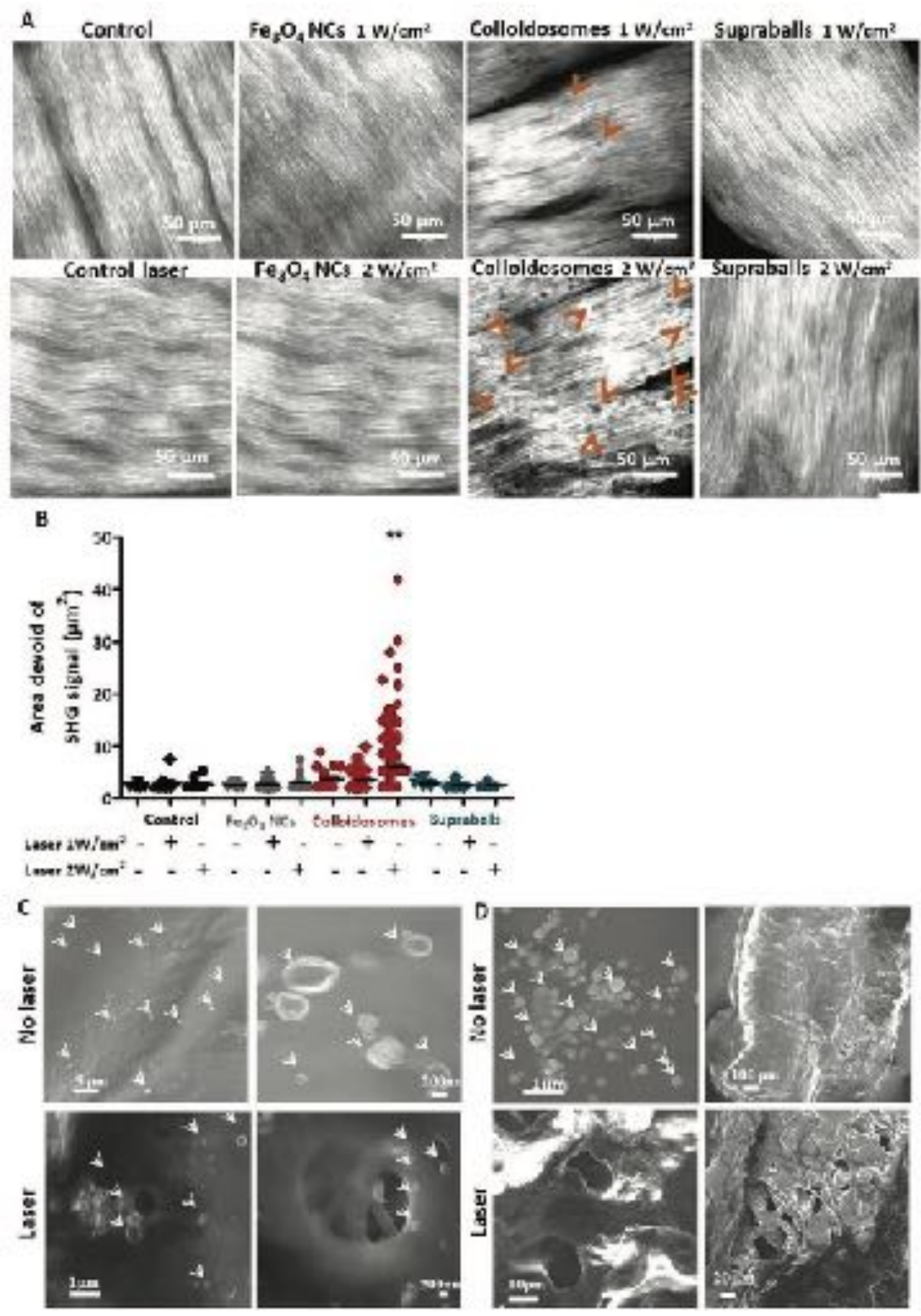

Figure 10. Colloidosome-mediated PTT induces collagen denaturation. A) Two photon second harmonic generation (SHG) microscopy images of sheep tendon collagen alone (control) or incubated with $\mathrm{Fe}_{3} \mathrm{O}_{4} \mathrm{NCs}$, colloidosomes and supraballs and subsequently irradiated with $808 \mathrm{~nm}$ laser a two different laser power $\left(1\right.$ and $\left.2 \mathrm{~W} \mathrm{~cm}^{-2}\right)$. Collagen denaturation is observed as areas devoid of collagen SHG signals 
within the dense collagen network (orange arrows). Scale bar $=50 \mu \mathrm{m}$. B) Quantification of the presence and size of the collagen denatured sites for the different conditions. (One-way ANOVA, Kruskal-Wallis, ** $p<0.01$ ). C) SEM images of fresh sheep tendon incubated with colloidosomes and irradiated with a NIR laser. Location of the colloidosomes is indicated with the white arrows. D) SEM images of supraballs deposited on the tendon and irradiated with a NIR laser. Location of the supraballs is indicated with the white arrows.

\section{Conclusion}

In this study we have focused on the photothermal and biological effects of $\mathrm{Fe}_{3} \mathrm{O}_{4} \mathrm{NC}$ self-assembled into two different conformations: colloidosomes and supraballs. The different conformations confer them with unique properties, that govern both their local light-to-heat conversion as well as their tumoral tissue distribution in comparison to isolated nanocrystals. Remarkably, colloidosomes and supraballs are capable of inducing extended tumor necrosis after a single 15 minutes NIR in vivo laser exposition and mild hyperthermia in a breast cancer model in mice. This impressive tissue damage correlates with enhanced cell death on tumor cell suspension and monolayers and collagen destructuration in tumor slices of a desmoplastic tumor and in a sheep tendon. However, these biological outcomes of PTT mediated by self-assemblies do not correlate with the global temperature increase that is measured by infrared camera. Indeed, dispersed $\mathrm{Fe}_{3} \mathrm{O}_{4} \mathrm{NC}$ exhibits higher global heating capacity than colloidosomes while their PTT biological effects are unsignificant. In contrast, colloidosomes and to a lesser extent supraballs induced potent and localized thermal damages both in tumor cells and collagen matrix. This is a unique demonstration that global heating measurements is neither representative of local energy deposition nor predictive of the biological outcomes of nanostructure-mediated PTT. Our findings emphasize that nanoparticle distribution and light to heat energy conversion must be controlled at the subtissular and subcellular scale in order to optimize the biological outcomes of "nanohyperthermia". This represents a paradigm shift in the field of nanoparticle-mediated hyperthermia.

Our study also reveal different phenomena that explain the outstanding properties of self-assemblies, in comparison to isolated nanocrystals, to optimize the NIR-induced local thermal damages in the biological environment: i) an enhanced energy accumulation in the hybrid self-assemblies with the organic phase playing the role of localized thermal resistance [15], ii) an optimized intralysosomal concentration of nanoheaters, iii) an optimized transfer of energy to the lysosome membrane that afford the affinity of colloidosomes to the cell membrane. All these features are direct consequences of the organization of the hybrid organic-inorganic selfassemblies and open new avenues for more precise control of photothermal conversion in the cellular and extracellular biological environment.

On top of these unique properties of hybrids as nanoradiators, we highlight very distinct distribution of the two hybrids and their dispersed building blocks $\left(\mathrm{Fe}_{3} \mathrm{O}_{4} \mathrm{NCs}\right)$ in the complex tumor microenvironment, taken as a whole (intratumoral administration) or by separating its different components (tumor cells, stromal cells, extracellular matrix). Indeed, $\mathrm{Fe}_{3} \mathrm{O}_{4} \mathrm{NCs}$ were mostly located in the ECM and macrophages, while supraballs were distributed partly in ECM and tumor cells. Owing to their different structure, flexibility and affinity for cell membrane, colloidosomes were shown to be more efficiently internalized by tumor cells than stromal cells and 
to target the tumor cells even in the competitive multicomponent environment of the breast tumor model. This very efficient targeting of tumor cells by colloidosomes also correlate with enhanced PTT-induced necrosis in the tumor, while dispersed $\mathrm{Fe}_{3} \mathrm{O}_{4} \mathrm{NC}$ have no significant effect. Here, we evidence that peculiar self-assemblies of nanocrystals allow for a better control of the tissular and intracellular distribution of the inorganic nanocrystals triggering different and more precise biological responses to the NIR irradiation. The complexity of the tumor microenvironment has been somehow overlooked in the research of nanomaterials for tumor therapy, which partly explain the low number of inorganic nanomedicines that have been translated into the clinics. Remarkably, using $\mathrm{Fe}_{3} \mathrm{O}_{4} \mathrm{NC}$ or their self-assemblies as colloidosomes and supraballs allows us targeting different components of the heterogeneous tumor ecosystem which is an important asset to envision new strategies of personalized therapy. One possible way of exploiting these differences for more personalized and precision medicine would be choosing the correct nano-assembly as function of the therapy target and the peculiarity of the tumor microenvironment of the patient. This offers the opportunity to adapt the choice of nanostructures to the particularity of the actual tumor (e.g. fibrosis level, macrophage infiltration, importance of fibroblasts) and to the intended biological outcome (tumor cell death, ECM destructuration, fibroblast depletion, macrophage depletion ...) for seeking a better control of therapy.

\section{Experimental Section}

Cell culture. A431 human epidermoid carcinoma cells (ATCC, CRL-1555) were cultured in Roswell Park Memorial Institute medium (RPMI) supplemented with $10 \%$ fetal bovine serum and $1 \%$ penicillin and maintained at $37^{\circ} \mathrm{C}$ and $5 \% \mathrm{CO}_{2}$. Cells were seeding density and cell culture differed according the experiment performed. Murine macrophage-like cell line RAW264.7 (ATCC, TIB-71), hTERT-HSC derived from human activated immortalized hepatic stellate cells kindly provided by Dr. L. Aoudjehane (ICAN, Paris, France) and MET-1 cell line (obtained from Robert Cardiff - University of California, Davis) were cultured in DMEM supplemented with $10 \%$ Fetal bovine serum (FBS), Penicillin/Streptomycin, L-Glucose and Sodium pyruvate (Gibco). For cell labeling with $\mathrm{Fe}_{3} \mathrm{O}_{4} \mathrm{NC}$, colloidosomes and supraballs, cells were incubated with the different nanoparticles at different concentrations according to the experiment for 24 hours at $37^{\circ} \mathrm{C}$ and $5 \% \mathrm{CO}_{2}$.

Quantification of iron uptake by cells in vitro. In order to study the uptake of the different nanoparticles in cells when incubated at [Fe] $28 \mu \mathrm{g} / \mathrm{mL}$ for 24 hours, the concentration of iron in A431, RAW 264.7 and hTERT-HSC cells was performed by ICP atomic emission spectrometer (model iCAP6200 duo. Thermo Fischer Scientific, analysis performed in the PARI platform, IPGP, Paris, France). For each iron measurement, cell pellets were digested in $289 \mu \mathrm{L}$ of $69 \%$ nitric acid (trace metal basic grade; Sigma) at room temperature overnight. The solutions were then diluted in ultrapure water for analysis. The calibration standards and the quality controls were provided by SCP SCIENCE and ChemLab. The analyzer drift is regularly corrected by quality controls measurements to ensure a drift lower than 5\%. An ASX-520 Autosampler was used. Argon 4.5 Linde (min, $99.995 \%$ ) was used as plasma and purge gas. All samples were analyzed in $2 \%$ nitric acid. 
Fibroblast sheets culture. Cell sheets were made with hTERT-HSC, as previously described [39]. 30,000 cells were plated in 6-well plates for 5-6 weeks. During this period, the cells were supplied with DMEM freshly supplemented with $50 \mu \mathrm{g} / \mathrm{mL}$ ascorbic acid (Sigma-Aldrich), three times per week. The fibroblast sheets were rinsed with PBS and incubated with the $\mathrm{Fe}_{3} \mathrm{O}_{4} \mathrm{NC}$, colloidosomes and supraballs at $28 \mu \mathrm{g} / \mathrm{mL}$ of iron for 24 hours at $37^{\circ} \mathrm{C}$ and $5 \% \mathrm{CO}_{2}$. The fibroblast sheets were then washed twice with $\mathrm{PBS}$ and fixed with $2 \%$

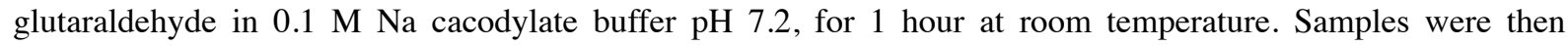
processed for Transmission Electron Microscopy as detailed in the following section.

Transmission Electron Microscopy. TEM images were acquired using a Hitachi HT7700 operating at $80 \mathrm{kV}$ (MIMA2 platform, INRA, Jouy-en- Josas, France). A431 cells were exposed to $\mathrm{Fe}_{3} \mathrm{O}_{4} \mathrm{NC}$, colloidosomes and supraballs at $28 \mu \mathrm{g} / \mathrm{mL}$ of iron for 24 hours at $37^{\circ} \mathrm{C}$. Following incubation cells were detached by trypsinization, washed twice with PBS and fixed with $2 \%$ glutaraldehyde in $0.1 \mathrm{M} \mathrm{Na}$ cacodylate buffer pH 7.2, for 1 hour at room temperature. Samples were then contrasted with Oolong Tea Extract (OTE) $0.5 \%$ in cacodylate buffer for 1 hour at room temperature, postfixed with $1 \%$ osmium tetroxide containing $1.5 \%$ potassium cyanoferrate for 1 hour at room temperature, gradually dehydrated in ethanol: $70 \%-5 \mathrm{~min}$ incubation, $90 \%-5$ min incubation, $100 \%$ - 5min incubation 3 times. Ethanol was then substituted gradually in mix of ethanol-Epon under vacuum for 1 hour and finally embedded in Epon (Delta microscopie - Labège France).

Thin sections $(70 \mathrm{~nm})$ were collected onto 200 mesh copper grids, and counterstained with lead citrate. Grids were examined with Hitachi HT7700 electron microscope operated at 80kV (Elexience - France), and images were acquired with a charge-coupled device camera (AMT).

Photothermal measurement of nanoparticles in aqueous solution. Photothermal measurements were made with an $808 \mathrm{~nm}$ NIR laser (Laser Diode Drivers, BWT) with adjustable power setting (0-5W). $100 \mu \mathrm{L}$ of aqueous nanoparticle dispersion at different concentrations were placed in a $0.5 \mathrm{~mL}$ tube (open lid). The tube was irradiated at $4 \mathrm{~cm}$ distance with a laser spot of $0.4 \mathrm{~cm}^{2}$. The laser power was adjusted at $1 \mathrm{~W} \mathrm{~cm}^{-2}$. The temperature was monitored using an infrared thermal imaging camera (FLIR SC7000) in real time, recording one frame per second.

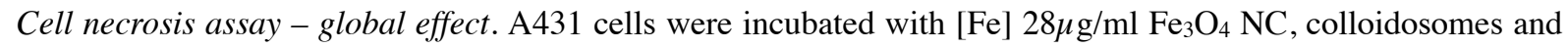
supraballs for $24 \mathrm{~h}$ in 6-well cell culture plates. Cells were then trypsinized, washed with PBS1X and counted. $1 \mathrm{x} 10^{6}$ cells were resuspended in 100 $\mu 1$ PBS $1 \mathrm{X}$ (500 $\mu 1$ tube). The cell suspension was then subjected to an 808 $\mathrm{nm}$ beam laser for $10 \mathrm{~min}\left(1 \mathrm{~W} / \mathrm{cm}^{2}\right.$, height $4 \mathrm{~cm}$ from the liquid/air interface, Laser Diode Drivers, BWT), and temperature was recorded with infrared camera SC7000 from FLIR Systems. To evaluate the global effects of heating, the irradiated cells were put back into Nunc LabTeck slides (Thermo Fisher) and cultured for 4 hours. To test the level of damage performed by the nanoparticle in cells, cell necrosis was evaluated. To do so, Chromatin Condensation \& Membrane Permeability Dead Cell Apoptosis Kit, purchased from Molecular Probes-Invitrogen Detection Technologies (Eugene, OR), was used according to the manufacturer's protocol. Briefly, the cells were washed with PBS were incubated with $1 \mu \mathrm{l}$ each of Hoechst 33342 , YO-PRO ${ }^{\text {TM }}$ dye and propidium iodide stock solution at $37^{\circ} \mathrm{C}$ in an atmosphere of $5 \% \mathrm{CO}_{2}$ for 15 minutes. The cells were viewed 
using a Andor Technology with Olympus JX81/BX61 Device/Yokogawa CSU Device spinning disk microscope (Andor Technology plc, Belfast, Northern Ireland) using appropriate filters. The dead cells were stained with redfluorescent propidium iodide dye whilst YO-PRO ${ }^{\mathrm{TM}}$ dye enters cells in apoptosis, the blue-fluorescent Hoechst 33342 stains the chromatin of the cells. 30 images were taken for each condition. All experiments were performed three times. To quantify the level of cell death and apoptosis the number of propidium iodide and YO$\mathrm{PRO}^{\mathrm{TM}}$ labeled nuclei, respectively, as well as Hoechst 33342 labeled nuclei were counted using ImageJ Cell Counter plugin.

Cell necrosis assay - local effect. 15000 A431 cells were seeded in each well of an 18 well $\mu$-slides (Ibidi, Germany). The cells were then incubated with $\mathrm{Fe}_{3} \mathrm{O}_{4} \mathrm{NC}$, colloidosomes and supraballs at $28 \mu \mathrm{g} / \mathrm{mL}$ of iron overnight and irradiated to an $808 \mathrm{~nm}$ beam laser for $10 \mathrm{~min}\left(1 \mathrm{~W} / \mathrm{cm}^{2}\right.$, height $4 \mathrm{~cm}$ from the liquid/air interface, Laser Diode Drivers, BWT). The cells were then incubated at $37^{\circ} \mathrm{C}, 5 \% \mathrm{CO}_{2}$ for 4 hours. Next the level of cell damage was tested using the Chromatin Condensation \& Membrane Permeability Dead Cell Apoptosis Kit following the same protocol described in the previous section. The cells were viewed using a Andor Technology with Olympus JX81/BX61 Device/Yokogawa CSU Device spinning disk microscope (Andor Technology plc, Belfast, Northern Ireland) using appropriate filters. The dead cells were stained with red-fluorescent propidium iodide dye whilst YO-PRO ${ }^{\mathrm{TM}}$ dye enters cells in apoptosis, the blue-fluorescent Hoechst 33342 stains the chromatin of the cells. 30 images were taken for each condition. All experiments were performed three times. To quantify the level of cell death and apoptosis the number of propidium iodide and YO-PRO ${ }^{\mathrm{TM}}$ labeled nuclei, respectively, as well as Hoechst 33342 labeled nuclei were counted using ImageJ Cell Counter plugin.

PTT on sheep tendon and second harmonic generation imaging and Scanning Electron Microscopy with a Field Emission Gun (SEM-FEG). Fresh sheep tendon was obtained from our local butcher. Tendon was cut (perpendicular to the fibers' orientation) using a sharp scalpel into 1-2 $\mathrm{cm}$-sized fragments, which were embedded in 5\% low-gelling-temperature agarose (type VII-A; Sigma-Aldrich) prepared in PBS. Slices (100 $\mu \mathrm{m})$ were cut (parallel to the fibers' direction) with a vibratome (VT 1000S; Leica) in a bath of ice-cold PBS. The slices were then placed on top of 0.4- $\mu \mathrm{m}$ organotypic culture inserts (Millicell, Millipore) in 35-mm petri dishes containing $1.1 \mathrm{~mL}$ RPMI 1640 without Phenol Red. [Fe] $100 \mu \mathrm{g}$ of $\mathrm{Fe}_{3} \mathrm{O}_{4} \mathrm{NC}$, colloidosomes and supraballs were deposited on the slices. The slices were then incubated for 2 hours at $37^{\circ} \mathrm{C}$ to allow the nanostructures penetration into the tissue. The slices were washed to remove all material that had not penetrated the slice. The slices were then irradiated with an $808 \mathrm{~nm}$ beam laser for $10 \mathrm{~min}\left(2 \mathrm{~W} / \mathrm{cm}^{2}\right.$, height $4 \mathrm{~cm}$ from the slice, Laser Diode Drivers, BWT).

In order to evaluate the damage produced by the PTT on the collagen network, the slices were imaged using inverted stand Leica SP5 microscope (Leica Microsystems GmbH, Wetzlar, Germany) coupled to a femtosecond Ti:sapphire laser (Chameleon, Coherent, Saclay, France) tuned at a wavelength of 810 or $850 \mathrm{~nm}$ for all experiments. SHG laser exposure parameters were set in order to enable image acquisition without inducing artefactual destruction of the tissue. SHG imaging exploits the non-centrosymmetric tightly packed arrangement of amino acids in collagen that exhibit unique optical properties in order to image them. The laser beam was 
circularly polarized and a Leica Microsystems HCX IRAPO 25×/0.95 W objective was used. Second harmonic generation (SHG - collagen structure) signal was detected in epi-collection through a 405/15nm bandpass filter and detected by NDD PMT detectors (Leica Microsystems) with a constant voltage supply, at constant laser excitation power, allowing direct comparison of SHG intensity values. Another way of evaluating the damage produced on the collagen network was evaluating with Scanning Electron Microscopy. After irradiation the collagen slices were directly deposited on a conductive double-faced adhesive carbon tape. The samples were carbon-coated before observations. Images were obtained with a SEM-FEG Zeiss Merlin Compact microscope operating at $10 \mathrm{kV}$ (MPQ laboratory, Université de Paris).

PTT on EGI-1 tumor slices and second harmonic generation imaging. Animal experiments were performed in accordance with the French Animal Research Committee guidelines and all procedures were approved by a local ethic committee (No 14678). $2 \times 10^{6}$ cells suspended in $60 \mu \mathrm{L}$ of PBS were mixed with $60 \mu \mathrm{L}$ of Matrigel ${ }^{\circledR}$ growth factor reduced (Corning) and implanted subcutaneously into the flank of 5-week-old female NMRI-nu $(\mathrm{nu} / \mathrm{nu})$ mice (Envigo, France). Mice were housed under standard conditions in individually ventilated cages enriched with a nesting material and kept at $22^{\circ} \mathrm{C}$ on a 12-h light/12-h dark cycle with ad libitum access to food and tap water. When the tumor volume reached $800-1000 \mathrm{~mm}^{3}$ (approximately 30-35 days after the injection of EGI-1 cells), tumors were considered ready for harvesting. The tumors were then resected and cut into $1-2 \mathrm{~cm}$ fragments. which were embedded in 5\% low-gelling-temperature agarose (type VII-A; Sigma-Aldrich) prepared in PBS. Slices $(100 \mu \mathrm{m})$ were cut (parallel to the fibers' direction) with a vibratome (VT 1000S; Leica) in a bath of ice-cold PBS. The slices were then placed on top of 0.4- $\mu \mathrm{m}$ organotypic culture inserts (Millicell, Millipore) in 35-mm petri dishes containing $1.1 \mathrm{~mL}$ RPMI 1640 without Phenol Red. [Fe] $100 \mu \mathrm{g}$ of $\mathrm{Fe}_{3} \mathrm{O}_{4} \mathrm{NC}$, colloidosomes and supraballs were deposited on the slices. The slices were then incubated for 2 hours at $37^{\circ} \mathrm{C}$ to allow nanoscturctures penetration into the tissue. The slices were washed to remove all material that had not penetrated the slice. The slices were then irradiated with an $808 \mathrm{~nm}$ beam laser for $10 \min \left(2 \mathrm{~W} / \mathrm{cm}^{2}\right.$, height $4 \mathrm{~cm}$ from the slice, Laser Diode Drivers, BWT). In order to evaluate the damage produced by the PTT on the collagen network, the slices were imaged using inverted stand Leica SP5 microscope (Leica Microsystems GmbH, Wetzlar, Germany) coupled to a femtosecond Ti:sapphire laser (Chameleon, Coherent, Saclay, France) tuned at a wavelength of 810 or $850 \mathrm{~nm}$ for all experiments. The laser beam was circularly polarized and a Leica Microsystems HCX IRAPO 25×/0.95 W objective was used. Second harmonic generation (SHG - collagen structure) signal was detected in epi-collection through a 405/15nm bandpass filter and detected by NDD PMT detectors (Leica Microsystems) with a constant voltage supply, at constant laser excitation power, allowing direct comparison of SHG intensity values.

In vivo studies in MET-1 tumor models.Animal experiments were performed in accordance with the French Animal Research Committee guidelines and all procedures were approved by a local ethic committee. 1 x $10^{6}$ cells suspended in $50 \mu \mathrm{L}$ of PBS were injected subcutaneously into the flank of a 6-week-old female FVB mice (Janvier France). Tumor growth was followed with a caliper, and tumor volume (V) was calculated as follows: xenograft volume $=\left(x y^{2}\right) / 2$ where $\mathrm{x}$ is the longest and $\mathrm{y}$, the shortest of two perpendicular diameters. When the 
tumor volume reached 150-200 $\mathrm{mm}^{3}$ (approximately 10 days after the injection of MET-1 cells), tumors were considered ready for treatment. $[\mathrm{Fe}]=150 \mu \mathrm{g}$ of $\mathrm{Fe}_{3} \mathrm{O}_{4} \mathrm{NC}$, colloidosomes and supraballs were injected intra tumorally within the MET-1 tumors. 24 hours after the injection, tumors were irradiation with an 808-nm at 2 W/ $\mathrm{cm}^{2}$ for $15 \mathrm{~min}$ (height from tumor skin $4 \mathrm{~cm}$, Laser Diode Drivers, BWT). Surface temperature was recorded with an infrared camera SC7000 from FLIR Systems during the laser treatment and analyzed using ResearchIR Software (FLIR). 24 hours after irradiation the animals were sacrificed and the tumor was resected for histological analysis

Histology and immunohistochemistry. Freshly harvested tumors were fixed overnight at $4{ }^{\circ} \mathrm{C}$ in a periodatelysine-paraformaldehyde solution [0.05 M phosphate buffer containing 0.1 M L-lysine (pH 7.4), $2 \mathrm{mg} / \mathrm{mL}$ $\mathrm{NaIO}_{4}$, and $10 \mathrm{mg} / \mathrm{mL}$ paraformaldehyde]. The tumors were dehydrated in graded solutions of ethanol and embedded in paraffin. For histology, five micrometer tissue sections were stained with hematoxylin / eosin / Saffron (HES) and Perls staining. Slices were then imaged with an optical microscope and analyzed. For immunohistochemistry labelling, five micrometer tissue sections were dewaxed. For F4/80 labeling, the antigen was retrieved with citrate solution $(\mathrm{pH} 7)$ preheated for $10 \mathrm{~min}$ at $95-98^{\circ} \mathrm{C}$. Endogenous peroxide was blocked for 10 min with $10 \%$ of hydrogen peroxide. The F4/80 antibody (D2S9R clone, Cell Signaling) was incubated at a 1/100 dilution. An automated staining system (Leica Bond) was used to perform the immunostaining. The antiF4/80 antibody was detected with a secondary anti-rabbit antibody, coupled to a HRP-coupled polymer (Leica, Bond Polymer Refine Detection, No. DS9800).

Statistical analysis. Results were analyzed using the GraphPad Prism 5.0 statistical software. Data are shown as means \pm standard error of the mean (SEM). For comparisons between two groups, parametric Student t-test or non-parametric Mann-Whitney test were used. For comparisons between more than two groups, parametric OneWay analysis of variance (ANOVA) test followed by a posteriori Kruskal-Walis test.

\section{Acknowledgments}

ANB received a $\mathrm{PhD}$ fellowship by the Institut thématique multi-organismes (ITMO) Cancer, the doctoral school Frontières du Vivant (FdV) - Programme Bettencourt and the Fondation ARC pour la recherche sur le cancer. This project was funded by the European Union's Horizon 2020 research and innovation program under grant agreements $\mathrm{N}^{\circ} 801305$ (NanoTbTech) and No 685795 (Nocanther).

We acknowledge Christine Péchoux (INRA, UMR 1313, Plateforme MIMA2, Jouy en Josas, France) for electron microscopy preparation and observation, Maryline Favier, Fabiola Ely-Marius and Rachel Onifarasoaniania from HistIM Plate-Form (Institut Cochin, Paris France), Stéphan Suffit for SEM experiments (Clean room facility, MPQ, Université de Paris, France), Laure Cordier for ICP-AES measurements that were supported by IPGP multidisciplinary program PARI, and by Paris-IdF region SESAME Grant no. 12015908, Emmanuel Donnadieu for fruitful discussion and Jelena Kolosnjaj-Tabi for the fibroblast sheet model.

\section{Conflict of Interest}

The authors declare no conflict of interest. 


\section{Keywords}

hyperthermia, nanocrystals self-assemblies, photothermal therapy, tumor microenvironment

Received: August 12, 2020 Revised: September 20, 2020

[1] Motte, L.; Billoudet, F.; Pileni, M.-P. Self-Assembled Monolayer of Nanosized Particles Differing by Their Sizes. J. Phys. Chem. 1995, 99, 16425-16429.

[2] Murray, C.B, Kagan, C.R. and Bawendi, M.G. Self-Organization of CdSe Nanocrystallites into ThreeDimensional Quantum Dot Superlattices. Science 1995, 270, 1335-1338.

[3] Mirkin, C. A.; Letsinger, R. L.; Mucic, R. C.; Storhoff, J. J. A DNA-Based Method for Rationally Assembling Nanoparticles into Macroscopic Materials Nature, 1996, 282, 607-609

[4] Rosi, N. L.; Mirkin, C. A. Nanostructures in biodiagnostics. Chemical Reviews 2005, 105, 1547-1562.

[5] Pileni, M.P. Nanocrystals self-assemblies: fabrication and collective properties. J. Phys. Chem. ,2001,105, 3358 - 3372

[6] Pileni, M.P. Supra- and nanocrystallinities: a new scientific adventure J.Phys. Cond.. Matter., 2011, 23, 503102

[7] Courty, A. Mermet,A. Albouy, P.A. Duval,E. and Pileni, M.P. Self-organized Ag-nanocrystals in fcc "supra" crystals: Vibrational Coherence. Nature materials, 2005,4, 395-398.

[8] Kang, Y.; Ye, X.; Chen, J.; Qi, L.; Diaz, R. E.; Doan-Nguyen, V.; Xing, G.; Kagan, C. R.; Li, J.; Gorte, R. J.; Stach, E. A. and Murray, C. B.Engineering Catalytic Contacts and Thermal Stability: Gold/Iron Oxide Binary Nanocrystal Superlattices for CO Oxidation J. Am. Chem. Soc. 2013, 135, 1499

[9] Pileni, M.P Impact of the metallic crystalline structure on the properties of nanocrystals and their mesoscopic assemblies. Acc. Chem. Res., 2017, 50, 1946-1955.

[10] Yang, Z., Altantzis, T., Zanaga, D., Bals, S., Van Tendeloo,G. and Pileni, M.P. Supracrystalline Colloidal Eggs: Epitaxial Growth and Freestanding Three-Dimensional Supracrystals in Nanoscaled Colloidosome. J.Amer. Chem.Soc, 2016, 138, 3493-3500

[11] Howse, J.R., Jone, R.A.L, Battaglia, G., Ducker, R.E., Leggett, G.J. and Ryan, A.J., Templated formation of giant polymer vesicles with controlled size distributions. Nat Mater, 2009. 8,. 507-11.

[12] Hickey, R.J., Koski, J., Meng, X., Riggleman, R.A., Zhang, P and Park, S.J. Size-controlled self-assembly of superparamagnetic polymersomes. ACS Nano, 2014. 8, 495-502.

[13] de Nijs, B.; Dussi, S.; Smallenburg, F.; Meeldijk, J. D.; Groenendijk, D. J.; Filion, L.; Imhof, A.; van Blaaderen, A. and Dijkstra, M., Entropy-driven formation of large icosahedral colloidal clusters by spherical confinement. Nature Materials 2014, 14, 56.

[14] Rossi, L.; Soni, V.; Ashton, D. J.; Pine, D. J.; Philipse, A. P.; Chaikin, P. M.; Dijkstra, M.; Sacanna, S.; Irvine, W. T. M., Shape-sensitive crystallization in colloidal superball fluids. Proc Natl Acad Sci U S A 2015, 112 (17), 5286-5290.

[15] Mazzanti, A.; Yang, Z.; Silva, M. G.; Yang, N.; Rizza, G.; Coulon, P.-E.; Manzoni, C.; de Paula, A. M.; Cerullo, G.; Della Valle, G.; Pileni, M.-P., Light-heat conversion dynamics in highly diversified waterdispersed hydrophobic nanocrystal assemblies. Proceedings of the National Academy of Sciences 2019, 116 (17), 8161-8166.

[16] Riley, R.S. and E.S. Day, Gold nanoparticle-mediated photothermal therapy: applications and opportunities for multimodal cancer treatment. Wiley Interdiscip Rev Nanomed Nanobiotechnol, 2017. 9(4). 
[17] Das, R., Rinaldi-Montes, N., Alonso, J., Amghouz, Z., Garaio, E., Garcia, J.A., Gorria, P., Blanco, J.A., Phan, M.H. and Srikanth Boosted Hyperthermia Therapy by Combined AC Magnetic and Photothermal Exposures in Ag/Fe3O4 Nanoflowers. ACS Appl Mater Interfaces, 2016. 8(38): p. 25162-9.

[18] Jaque, D., Martinez Maestro, L., del Rosal, B., Haro-Gonzalez, P., Benayas, A., Plaza, J.L., Martin Rodriguez, E. and Garcia Solé, J. Nanoparticles for photothermal therapies. Nanoscale, 2014. 6(16): p. 9494-530.

[19] Tabi, J.K., Javed, Y., Luciani, N., Pellegrino, T., Alloyeau D. and Gazeau, F. Biotransformations of magnetic nanoparticles in the body Nanotoday, 2016, 11, 280-284

[20] Volatron, J., Carn, F. Tabi, J.K., Javed, Y.,Vuong, Q.L., Gossuin, Y., Menager, C. Luciani, N., Carron, G., Hemadi, M., Alloyeau D. and Gazeau, F. Ferritin Protein Regulates the Degradation of Iron Oxide Nanoparticles Small, 2017, 13, 1602030

[21]Zijian Zhou, Z., , Rui Tian, R., Wang, Z., , Zhen Yang, Z.; , Liu, Y., Liu, G., Wang, R., Gao, J., Song, J., Nie, L. and Chen, X. Artificial local magnetic field inhomogeneity enhances $\mathrm{T}_{2}$ relaxivity Nat. Commun., 2017, 15468, 1-4

[22] Nie, L and Chen, X. Structural and functional photoacoustic molecular tomography aided by emerging contrast agents Chem. Soc. Rev. 2014, 43, 7132-7110

[23] Zhou, Z., Song, J., Tian, R., Yang, Z., Yu, G., Lin, L., Zhang, G., Fan, F., Niu, G., Nie, L., Chen, X. Activable single oxygen generation from lipi hydroperoxide nanoparticles forcancer therapy Angew. Chem. Int. Edit., 2017, 56(, 6492.

[24] Magnetic (Hyper)Thermia or Photothermia? Progressive Comparison of Iron Oxide and Gold Nanoparticles Heating in Water, in Cells, and In Vivo. Espinosa, J.K., Tabi, J.K., Hassan, A.A., Sangnier, A.P., Curcio, A., Silva, A.K.A., Di Corato, R. Neveu, S., Pellegrino, T., Liz-Marzan and Wilheim, C. Adv. Funct. Mat., 2018, 12,1803660

[25] Levy, M. Wilhelm, C., Luciani, N., Deveaux, V., Gendron, F., Luciani, A., Decaud, M and Gazeau, F. Nanoscale, 2011, 3, 4402-4410

[26] Nicolas-Boluda, A., Yang, Z., Dobryden, I., Carn, F., Winckelmans, N., Pechoux, C., Bonville, P., Bals, S., Claesson, P.M., Gazeau, F. and Pileni, M.P. Intracellular Fate of Hydrophobic Nanocrystal Self-Assemblies in Tumor Cells. Advanced Functional Materials 2020, https://onlinelibrary.wiley.com/doi/10.1002/adfm. 202004274

[27] Dobryden, I., Yang, Z., Claesson, P.M. and Pileni, M.P Water dispersive magnetic suprastructures: an organizational impact on nanomechanical properties. Submitted for publication

[28] This iron concentration was chosen to be coherent with our previous data [26] from which we have quantitively information concerning the lysosomal density, the localization of iron oxide nanocrystals and their organization within the lysosomes. However, a cytotoxicity assay confirms no toxicity of such assemblies above $112 \mathrm{mg} / \mathrm{mL}$

[29] The experiments were performed at $25^{\circ} \mathrm{C}$ instead of $37^{\circ} \mathrm{C}$ which is the normal temperature for cells to grow because our experimental set up for irradiating the cell pellet was not thermalized to $37^{\circ} \mathrm{C}$. Nevertheless it is of interest to start from $25^{\circ} \mathrm{C}$ as it critically amplify the local versus global heating differences between the nanostructures :

[30] Dias, J.T., Mros, M., del Pino, P., Rivera, S., Grazu, V. and de la Fuente, J.M. DNA as a Molecular Local Thermal Probe for the Analysis of Magnetic Hyperthermia. Angewandte Chemie (International ed. in English), 2013. 52. 11526-11529,

[31] Riedinger, A., Guardia, P., Curcio, A., Garcia, M.A., Cingolani, R., Manna, L. and Pellegrino, T Subnanometer Local Temperature Probing and Remotely Controlled Drug Release Based on AzoFunctionalized Iron Oxide Nanoparticles. Nano Letters, 2013. 13, 2399-2406. 
[32] Pérez-Hernández M, Del Pino P, Mitchell SG, Moros M, Stepien G, Pelaz B, Parak WJ, Gálvez EM, Pardo J, de la Fuente JM. Dissecting the molecular mechanism of apoptosis during photothermal therapy using gold nanoprisms. ACS Nano, 2015. 9(1): p. 52-61.

[33] Bastos, A.R.N., Brites, C.D.S., Brites, C.D., Rojas-Gutierrez, P.A., DeWolf, C., Ferreira, R.A.S., Capobianco,J.A and Carlos, L.D., Thermal Properties of Lipid Bilayers Determined Using Upconversion Nanothermometry. Advanced Functional Materials, 2019. 29, 1905474.

[34] Groth-Pedersen, L. and M. Jäättelä, Combating apoptosis and multidrug resistant cancers by targeting lysosomes. Cancer letters, 2013. 332, 265-274.

[35] Boya, P. and G. Kroemer, Lysosomal membrane permeabilization in cell death. Oncogene, 2008. 27, 6434-51.

[36] Clerc, P.Jeanjean, P., Hallali, N., Gougeon, M., Pipy, B., Carrey, J., Fourny, D. and Gigoux, V.Targeted Magnetic Intra-Lysosomal Hyperthermia produces lysosomal reactive oxygen species and causes Caspase-1 dependent cell death. J Control Release, 2018, 270, 120-134.

[37] Fourmy, D., J. Carrey, and V. Gigoux, Targeted nanoscale magnetic hyperthermia: challenges and potentials of peptide-based targeting. Nanomedicine, 2015. 10, 893-896.

[38] Note no toxicity was observed neither on different cell types nor by it or iv injection keeping mice in good health for more than three months

[39] Bonvalot, S., Rutkowskki, P.L., Thariat, J., Carrere, S., Ducassou, A., Sunyach, M.P., Agoston, P., Hong, A.,Mervoyer, A., Rastrelli, M., Moreno, V., Li, R.K., Tiangco, B., Herraez, A.C., Gronchi, A., Mangel, L.,Sy-Ortin, T., Hohenberger, P., de Baere, T., Le Cesne, A., Helfre, S., Saada-Bouzid, E., Borkowska, A., Anghel, R., Co, A., Gebhart, M., Kantor, G., Montero, A., Loong, H.H, Verges, R., Lapiere, L.L., Dema, S., Kacso, G., Austen, L., Moureau-Zabotto, L., Servois, V., Wardelmann, E., Teerrier, P., Lazar, A.J., Bovee, J.V.M, Le Pechoux, C., Papai, Z. NBTXR3, a first-in-class radioenhancer hafnium oxide nanoparticle, plus radiotherapy versus radiotherapy alone in patients with locally advanced soft-tissue sarcoma (Act.In.Sarc): a multicentre, phase 2-3, randomised, controlled trial [published correction appears in Lancet Oncol. 2019 Sep;20(9):e468]. Lancet Oncol. 2019;20, 1148-1159.

[40]Casal, R. F., Schwalk,A.J., Fowlkes, N., Aburto, R.R., Norton,W., Dixon, K.A., Lin, S.H., Shaitelman, S., Chintalapani, G. and Hill. L."Endobronchial ultrasound-guided injection of NBTXR3 radio-enhancing nanoparticles into mediastinal and hilar lymph nodes: a swine model to evaluate feasibility, injection technique, safety, nanoparticle retention and dispersion." Journal of thoracic disease, 2020, 12, 2317-2324 .

[41] Satiya, J.; Schwartz, I.; Tabibian, J. H.; Kumar, V.; Girotra, M. Ablative Therapies for Hepatic and Biliary Tumors: Endohepatology Coming of Age. Trans. gastroenterol. and hepatol. 2020, 5, 15 -18

[42] Alvarez-Sań chez, M. V.; Napoleó n, B. Review of Endoscopic Radiofrequency in Biliopancreatic Tumours with Emphasis on Clinical Benefits, 2016, 22, 8257-8270

[43] Balkwill, F.R., M. Capasso, and T. Hagemann, The tumor microenvironment at a glance. Journal of Cell Science, 2012.125, 5591

[44] Son, B., Lee, S., Youn, H., Kim, E.G., Kim, W. andYoun, B.H. The role of tumor microenvironment in therapeutic resistance. Oncotarget, 2017. 8, 3933-3945.

[45] Nicolás-Boluda, A., Vaquero, J., Laurent, G., Renault, G., Bazzi, R., Donnadieu, E., Roux, S., Fouassier, L. and Gazeau, F.Photothermal Depletion of Cancer-Associated Fibroblasts Normalizes Tumor Stiffness in Desmoplastic Cholangiocarcinoma. ACS Nano, 2020. 14, 5738-5753.

[46] Kolosnjaj-Tabi, J., Di Corato, R., Lartigue, L., Marangon, I.,Guardia, P., Silva, A.K.A., Luciani, N., Clément, O., Flaud, P., Singh, J.V., Pellegrino, T., Wilhelm, C. and Gazeau, F. Heat-generating iron oxide nanocubes: subtle "destructurators" of the tumoral microenvironment. ACS Nano, 2014. 8, 4268-4283. 
[47] Sosale, N.G., Rouhiparkouhi,T., Bradshaw, A.M., Dimova,R., Lipowsky,R. and Discher, D Cell rigidity and shape override CD47's “self”-signaling in phagocytosis by hyperactivating myosin-II. Blood, 2015. 125, $542-552$.

[48] Anselmo, A.C. and S. Mitragotri, Impact of particle elasticity on particle-based drug delivery systems. Adv Drug Deliv Rev, 2017, 108, 51-67.

[49] Anselmo, A.C., Zhang, M., Kumar, S., Vogus, D.R., Menegatti, S., Helgeson, M.E. and Mitragotri, S. Elasticity of nanoparticles influences their blood circulation, phagocytosis, endocytosis, and targeting. ACS Nano, 2015, 9, 3169-3177.

[50] Yi, X. and H. Gao, Cell membrane wrapping of a spherical thin elastic shell. Soft Matter, 2015. 11, $1107-1115$.

[51] Hartmann, R., Weidenbach, M., Neubauer, M., Fery, A.,and Parak, W.J. Stiffness-dependent in vitro uptake and lysosomal acidification of colloidal particles. Angew Chem Int Ed Engl, 2015. 54, 1365-8.

[52] Sun, H., ..E.H.H., Yan, Y., Cui,J., Dai, Q., Guo, J., Oiao, G.G. and Caruzo The role of capsule stiffness on cellular processing. Chem Sci, 2015. 6, .3505-3514.

[53] Pillet, F., Gibot, L., Madi, M., Rols, M.P.and Dague, E.Importance of endogenous extracellular matrix in biomechanical properties of human skin model. Biofabrication, 2017, 9, 025017.

[54] Marangon, I., Silva, A.A.K, Guilbert, T., Kolosnjaj-Tabi, J., Marchiol, C., Natkhunarajak, S., Chamming's, F., Menard-Moyon, C., Bianco, A., Gennisson, J.L, Renault, G. and Gazeau, F. Tumor Stiffening, a Key Determinant of Tumor Progression, is Reversed by Nanomaterial-Induced Photothermal Therapy. Theranostics, 2017, 7, 329-343.

[55] Bredfeld, J., Liu, Y., Pehlke, C.A., Conklin, M.W.,Szulczewski, J.M., Inman, D.R., Keely, P.J., Nowark, R.D., Mackie, T.R. and Eliceiri, K.W.Computational segmentation of collagen fibers from second-harmonic generation images of breast cancer. J Biomed Opt, 2014. 19, 16007. 